\title{
The climatic debt of loggerhead sea turtle populations in a warming world
}

\author{
Monsinjon Jonathan ${ }^{1,{ }^{*}}$, Wyneken Jeanette ${ }^{2}$, Rusenko Kirt ${ }^{3}$, Lopez-Mendilaharsu Milagros ${ }^{4}$, \\ Lara Paulo ${ }^{4}$, Santos Alexsandro ${ }^{4}$, Dei Marcovaldi Maria A. G. ${ }^{4}$, Fuentes Mariana M. P. B. ${ }^{5}$, \\ Kaska Yakup ${ }^{6}$, Tucek Jenny ${ }^{7}$, Nel Ronel ${ }^{7}$, William Kristina L. ${ }^{8}$, Leblanc Anne-Marie ${ }^{9}$, Rostal David ${ }^{9}$, \\ Guillon Jean-Michel ${ }^{1}$, Girondot Marc ${ }^{1}$
}

1 Univ Paris Saclay, Univ Paris Sud, Lab Ecol Systemat Evolut, CNRS,AgroParisTech, F-91405 Orsay, France.

2 Florida Atlantic Univ, Dept Biol Sci, Boca Raton, FL 33431 USA.

3 Gumbo Limbo Nat Ctr, 1801 N Ocean Blvd, Boca Raton, FL 33432 USA.

4 Fundacao Pro Tamar, Rua Rubens Guelli,134 Sala 307, Salvador, BA, Brazil.

${ }^{5}$ Florida State Univ, Dept Earth Ocean \& Atmospher Sci, Marine Turtle Res Ecol \& Conservat Grp, North Woodward Ave, Tallahassee, FL 32306 USA.

6 Pamukkale Univ, Sea Turtle Res Ctr DEKAMER, Denizli, Turkey.

7 Nelson Mandela Univ, Dept Zool, ZA-6031 Port Elizabeth, South Africa.

${ }^{8}$ Caretta Res Project, POB 9841, Savannah, GA 31412 USA.

${ }^{9}$ Georgia Southern Univ, Dept Biol, Statesboro, GA 30460 USA.

* Corresponding author : Jonathan Monsinjon, email address : jonathan.monsinjon@gmail.com

\begin{abstract}
:
Phenological shifts, by initiating reproductive events earlier, in response to advanced seasonal warming is one of the most striking effects currently observed in wild populations. For sea turtles, phenological adjustment to warming conditions could be the most effective short-term adaptation option against climate change. We calculated future phenological changes required in seven important loggerhead (Caretta caretta) nesting populations to continue achieving a high hatching success and a sex ratio that lies within current ranges. Considering temperature-mediated phenological changes, we found that most populations (six out of seven) will not be able to keep pace with a warming climate. Under an optimistic climate warming scenario (RCP4.5), these populations will face a climatic debt, that is, a difference between required and expected phenological changes, and warming will substantially reduce hatching success and induce a feminization of hatchlings, which may jeopardize their reproductive sustainability. Our approach offers the possibility to quantify the efficiency of phenological shifts in oviparous reptiles by considering physiological, developmental and phenological processes.
\end{abstract}




\section{Highlights}

- We assess the adaptive potential of phenological shifts in 7 sea turtle populations. Few populations may be able to stay synchronized with suitable thermal conditions. Hatchling survival may be substantially reduced in important populations. Nearly 100\% female-biased hatchling sex ratios are expected in important populations.

Keywords : Climate change, Phenotypic plasticity, Phenology, Hatching success, Sex ratio, Embryonic development, Incubation, Thermal tolerance, Reptile, Caretta caretta 
47 Current climatic changes affect species' abundance, distributions, phenology, physiology and 48 behavior (Bellard et al., 2012; Parmesan, 2006; Root et al., 2003). Such modifications at 49 population- and species-levels will undoubtedly scale toward community and ecosystem 50 levels, for example by disrupting trophic interactions (Walther, 2010). Assessing the 51 vulnerability of species under different climate scenarios is challenging yet it is a prerequisite 
for developing and prioritizing conservation management strategies. Species with highly heritable variability and short generation time are expected to respond rapidly to selection by microevolution of determinant traits, provided that they benefit from sufficient genetic diversity (Bradshaw and Holzapfel, 2006; Nogués-Bravo et al., 2018; Visser, 2008). In contrast, species with long generation times might be limited in their ability to keep up with the current rate of biotic and abiotic changes.

For these species, plasticity in behavior and physiology has the potential to compensate for rapid environmental shifts, allowing them to effectively track of their climate envelope (Chevin et al., 2010; Huey et al., 2012; Refsnider and Janzen, 2012). Many species are already shifting spatially (to higher latitudes or altitudes) and temporally (initiating reproductive events earlier or later in the season) (Parmesan, 2006; Root et al., 2003). For instance, several species of birds are laying their eggs 8.8 days earlier in 25 years in the United Kingdom (Crick et al., 1997). Such phenotypic plasticity may be adaptive if it enables a species to match with its resources or maladaptive if it creates a mismatch with available resources (Charmantier et al., 2008; Visser et al., 2012). Ectotherms are expected to be especially vulnerable to changes in their thermal environment because virtually all their life history traits depend on ambient temperatures, which in turn, affects fitness of individuals (Deutsch et al., 2008; Tewksbury et al., 2008). Temperature can even be viewed as an ecological resource for ectotherms (Magnuson et al., 1979) and especially for oviparous reptiles with temperature-dependent sex determination (TSD), such as sea turtles, because it allows or constrains embryonic development and directs sex ratio, which influence population viability (Hulin et al., 2009; Mitchell et al., 2010).

Six out of the seven sea turtle species are already endangered (IUCN, 2016) and may be under further threat as climate change progresses (Fuentes et al., 2013; Hamann et al., 2013). In their life history, like in all oviparous reptiles, the incubation stage is particularly 
sensitive to temperatures. Once the eggs are laid, the development of embryos is submitted to environmental factors that are highly dependent on climatic conditions experienced during the incubation period, without any possibility to avoid detrimental conditions. In sea turtles, both the hatching success and the sex of hatchlings depend on incubation temperatures. Constant temperature experiments shown that hatching occurs within a narrow thermal range (roughly 25-35 ${ }^{\circ} \mathrm{C}$ ) (Howard et al., 2014), with a steep threshold at lower temperatures under which development fails and at higher temperatures over which embryos die. Predicting the hatching success of nests in natural conditions remains challenging because temperature varies during the whole incubation period. Current temperature regimes may already reach or exceed the upper limit for successful development as evidenced by low incubation success observed at several nesting beaches (Horne et al., 2014; Rafferty et al., 2017; Valverde et al., 2010). Warming temperatures are thus expected to put the reproduction of many populations at risk.

In addition, sea turtles exhibit Temperature-dependent Sex Determination (TSD), producing females at high incubation temperatures and males at low incubation temperatures (Yntema and Mrosovsky, 1980). Many nesting sites already produce predominantly females, with a bias increasing toward nearly $100 \%$ females in some of them (Hays et al., 2017; Jensen et al., 2018). A further increase in incubation temperatures could dramatically jeopardize the production of males, and, in turn, these populations' long-term reproductive success. An adaptation to increasing temperatures could be achieved the microevolution of the pivotal temperature (i.e., the temperature at which $50 \%$ of each sex may occur). However, this scenario seems unlikely because (i) this trait is relatively conserved among populations (Hulin et al., 2009), which suggests strong genetic constraints, (ii) long generation times should hamper rapid genetic selection of individuals that might deviate, and (iii) the effective heritability of pivotal temperatures in turtles is low in natural conditions (Bull et al., 1982; McGaugh and Janzen, 2011; Refsnider and Janzen, 2015). Sea turtles are also known for natal 
homing behavior and a high degree of nest site fidelity (Bowen et al., 1994b; Bowen and Karl, 2007; Miller, 1997). The latter trait may constrain rapid large-scale spatial shifts toward more suitable thermal conditions for egg development. Without such plasticity in nest site choice, low rates of embryo survival and highly female-biased sex ratios may arise in the context of global warming (Fuentes et al., 2011; Poloczanska et al., 2009). Therefore, shifting the nesting season might be the most efficient short-term option for sea turtles to adapt to the current rate of thermal changes.

Earlier nesting in response to warmer environmental temperatures has been observed in a fresh water turtle (Chrysemys picta) (Schwanz and Janzen, 2008), in loggerhead sea turtles (Caretta caretta) (Hawkes et al., 2007; Lamont and Fujisaki, 2014; Mazaris et al., 2008; Monsinjon et al., 2019; Patel et al., 2016; Pike et al., 2006; Weishampel et al., 2004; Weishampel et al., 2010) and in green sea turtles (Chelonia mydas) (Weishampel et al., 2010). However, whether this phenotypic plasticity in nesting behavior will enable sea turtles to overcome warming impacts at nesting beaches remains to be investigated. Here we address this issue by applying the concept of "climatic debt", previously applied to the spatial distribution of bird and butterfly communities (Devictor et al., 2012), to seven loggerhead nesting populations. Briefly, the theoretical poleward range shift that a species should undertake to track its thermal niche is calculated and compared to a measured real-world response. In other words, a "climatic debt" can be viewed as the lag between environmental changes and the species' or population's response, depending on its ability to stay synchronized with previous conditions (i.e., the difference in time between required and observed or expected phenological shifts). Given that sea turtle populations are unlikely to fully track of suitable thermal conditions at nesting beaches by shifting spatially, we applied this concept at a temporal scale by addressing the following questions: What would be the 
populations to continue producing a hatching success and a sex ratio that lie within current ranges? Would expected temperature-induced phenological shifts be sufficient to reach this goal (i.e., to pay the "climatic prices") or would populations still face a "climatic debt", that is, a positive difference between the "climatic price" and the expected phenological shift?

Combining physiological, developmental and phenological processes, we developed two indices: A Hatching Success Index (HSI) that accounts for the number of nests successfully laid and a Sex Ratio Index (SRI) that accounts for the number of nests successfully laid and the proportion of surviving embryos. We forecasted the hatching success and the sex ratio of seven important loggerhead nesting populations at a global scale (Figure 1) within four Regional Management Units (RMUs) (Wallace et al., 2010) under current conditions and under two warming scenarios (RCP4.5 and RCP8.5) (IPCC, 2014). We first assumed the timing of nesting seasons will remain unchanged until 2100 and we explored how phenological shifts could buffer detrimental effects of rising temperatures by shifting the nesting seasons from 0 to 365 days earlier. Finally, we calculated the climatic debts by comparing the climatic prices to realistic expected phenological changes ( 7 days earlier per degree Celsius increase in sea surface temperature) (Weishampel et al., 2004).

\section{MATERIALS AND METHODS}

\section{Field data}

Nest temperature was recorded at several nesting sites within the following Regional Management Units (RMUs) (Wallace et al., 2010) of the loggerhead sea turtle: Mediterranean, Northwest Atlantic, Southwest Atlantic and Southwest Indian (information summarized in Supplementary material Table A1). Some data are presented here, while the remaining are already published. For the latter, we used only temperature data recorded in 
natural conditions. Temperatures were recorded within several nests for each site

152 (Supplementary material Table A1) using temperature data loggers placed in the middle of the clutches while females were laying their eggs $(\approx 45 \mathrm{~cm}$ deep $)$. Data loggers were excavated when hatchlings emerged from the nest or several days later. Temperature data recorded outside the incubation period (i.e., before the laying date or after the emergence date) were omitted.

The number of nests was surveyed daily by patrols at the seven nesting beaches during a period of the year specific to each monitoring program (information summarized in Supplementary material Table A2). We omitted nest attempts (false crawls) if the data set contained such information. Nests were counted at Dalyan Beach, Turkey, at Blackbeard Island and Wassaw Island, Georgia, at Boca Raton, Florida, at Praia do Forte and Rio de Janeiro, Brazil, and at Bhanga Nek, South Africa (Figure 1).

\section{Overview of the modeling approach}

For the seven nesting populations studied (Figure 1, see section "Field data"), we predicted a hatching success index and a sex ratio index according to scenarios for future area-specific changes in air temperature and global changes in ocean temperature (IPCC, 2014) (Supplementary material Table A3). Those indices were first calculated assuming that the timing of nesting seasons will not shift until 2100 (Figure 2). Thereafter, we shifted nesting seasons each day from 0 to 365 days earlier and we calculated the resulting hatching success and sex ratio indices, which enabled quantifying respective climatic prices (i.e., phenological shifts, in number of days earlier, required for projected indices to reach the lower limit of current ranges, Figure 2). Finally, we calculated the climatic debts (in number of days) by subtracting expected future temperature-induced phenological shifts from climatic prices. To project future temperature-induced phenological shifts, we assumed that a $1{ }^{\circ} \mathrm{C}$ increase in sea surface temperature will shift a nesting season 7 days earlier (Weishampel et al., 2004). Based 
on this linear relationship, $+1.19^{\circ} \mathrm{C}$ and $+2.89^{\circ} \mathrm{C}$ increases in ocean temperature (two warming scenarios: respectively, RCP4.5 and RCP8.5) (IPCC, 2014) (Supplementary material Table A3) would advance the whole nesting seasons 8.3 and 20.2 days earlier, respectively. Negative climatic debts indicate that phenological shifts can effectively offset detrimental effects of warming temperatures whereas positive climatic debts indicate that phenological shifts do not allow populations to track of their thermal niche (Figure 2). Hatching success and sex ratio indices resulting from future temperature-induced phenological shifts were calculated (Figure 2).

Following an elaborate modeling approach, it is possible to predict the temperature within the nest, the incubation duration, the hatching success, and the sex ratio (Figure 3). First, nest temperature was reconstructed based on a correlative model that links the temperature recorded within natural nests and environmental temperatures, such as air temperature and sea surface temperature, at nesting beaches (Figure 3.1). This step enables production of long-term time series of nest temperatures using projections from global climate models. We accounted for metabolic heating (i.e., the temperature difference between the nest and the adjacent incubation substratum), which is a characteristic of sea turtle nests due to their large clutch sizes (Booth and Astill, 2001; Broderick et al., 2001; Godfrey et al., 1997; Godley et al., 2001), and we reconstructed natural daily thermal fluctuations because they affect sex determination (Georges, 2013; Georges et al., 2005; Georges et al., 1994). Second, embryonic growth (in terms of carapace size) was modeled based on the Thermal Reaction

196 Norm (TRN) for growth rate inferred from nest temperatures, incubation durations and hatchling measurements (straight carapace length of hatchlings), combined with a growth function (Figure 3.2). When iteratively applied to time series of reconstructed nest temperatures, this approach provides information about embryonic development such as the incubation period and the location of the ThermoSensitive Period (TSP) of development for 
sex determination (i.e., the period during which temperature influences sex determination).

202 Third, hatching success was estimated by a model linking the average nest temperature to the Thermal Tolerance Curve (TTC) inferred using constant temperature experiments (Figure 3.3). Fourth, Constant Temperature Equivalents (CTEs) were converted into sex ratio estimates based on the TRN for sex ratio inferred using constant temperature experiments (Figure 3.4). Fifth, the dynamics of nesting activity was inferred based on the number of nests counted during monitoring surveys (Figure 3.5), which enabled including the temporal window within which nests are incubating. Finally, we calculated hatching success and sex ratio indices per season by including the number of nests laid per day (Figure 3.6).

\section{Reconstructing nest temperatures}

211 We modeled past Nest Temperatures (NT) based on a previously published method (Girondot 212 and Kaska, 2014b; Monsinjon et al., 2017a; Monsinjon et al., 2017b). Nest temperature 213 correlates with Air Temperature (AT) and Sea Surface Temperature (SST) in front of the 214 beach (Girondot and Kaska, 2014b). We collected such data from the European Centre for

215 Medium-Range Weather Forecasts (ECMWF) data sets, which provide temperature every 6 $216 \mathrm{hrs}$ (UTC) for several decades at $0.125^{\circ}$ resolution (Dee et al., 2011). Sea Surface

217 Temperature (SST) and Air Temperature (AT) at a height of $2 \mathrm{~m}$ were extracted from the $1^{\text {st }}$ 218 January 1979 to the $31^{\text {st }}$ December 2016 at geographic coordinates closest to the location of 219 nesting sites (distances between these geographic coordinates and the exact position of nesting sites ranged from 1.2 to $19 \mathrm{~km}$, Supplementary material Table A4). We modeled the daily mean temperature and the metabolic heating using a generalized linear mixed model with Gaussian distribution and identity link function (Monsinjon et al., 2017b) with the mixed effect being the nest identity. Natural daily thermal fluctuations were reconstructed as they can strongly affect sex determination (Georges, 2013; Georges et al., 2005; Georges et al., 1994). We calculated the average daily amplitudes of temperatures (AmpT) using daily 
maximum (from noon to noon) and daily minimum (from midnight to midnight) (Eccel, 2010) for all days and all nests, independently for each nesting sites. We also calculated the average time of the day when daily maxima and daily minima occur (respectively, Ti.Max and Ti.Min). After site-specific long-term time series of mean nest temperatures were reconstructed, we replaced daily mean by daily maximum (mean+AmpT/2) and daily minimum (mean-AmpT/2) that we set at Ti.Max and Ti.Min respectively. Site-specific parameters used to predict NT are presented in Supplementary material Table A4 (see also Supplementary material Note A1). This modeling approach allowed for an accurate prediction of nest temperature (Supplementary material Note A1, Figure A1).

We forecasted NT based on region-specific scenarios of changes in air temperature and a global scenario of changes in ocean temperature (IPCC, 2014) (Supplementary material Table A3). We chose an optimistic scenario of Representative Concentration Pathway (RCP) in greenhouse gas concentration that predicts a rising radiative forcing that will stabilize at $+4.5 \mathrm{~W} . \mathrm{m}^{-2}$ after 2100 as compared to preindustrial values, assuming a decrease in emissions of $\mathrm{CO}_{2}$ after 2040 (RCP4.5) (Moss et al., 2010). We also chose to make predictions under a more pessimistic scenario. This extreme scenario predicts a radiative forcing that will reach $+8.5 \mathrm{~W} \cdot \mathrm{m}^{-2}$ by 2100 as compared to preindustrial values and will keep rising afterward assuming no decrease in emissions of $\mathrm{CO}_{2}$ (RCP8.5) (Moss et al., 2010). These data were extracted from the KNMI (Koninklijk Nederlands Meteorologisch Instituut) Climate Explorer website (https://climexp.knmi.nl/plot_atlas_form.py). Briefly, the KNMI interface allows the user to select the region (here defined by IPCC Working Group 1), the data set (here Coupled Model Intercomparison Project 5 for IPCC's Fifth Assessment Report), the variable (here near-surface temperature), the scenario of RCP in greenhouse gas concentration (here RCP4.5 and RCP8.5) and the periods to be compared to obtain anomalies (here anomalies as compared with the 1979-2016 period). Projected temperature anomalies were extracted for the 
following regions: North-East Brazil, Eastern-North-America, Southern-Africa and South-

252 Europe-Mediterranean (summarized in Supplementary material Table A3). We added projected (region-specific) increases in temperature to AT time series previously extracted from ECMWF data sets. We also extracted the projected increase in ocean temperature at the scale of the world, which was added to SST time series previously extracted from ECMWF data sets. Future NT is then reconstructed following the method described above but this time using modified time series of AT and SST. These new NT time series are forecasts for the 2062-2100 period while considering the 1979-2016 period as a baseline.

\section{Modeling embryonic development}

The size of an embryo according to the temperature experienced within the nest can be modeled based on the Thermal Reaction Norm (TRN) for growth rate using an equation that describes the effect of temperature on the growth rate along with an equation that describes the progression of embryo size during incubation (Girondot and Kaska, 2014a). This method has been implemented to estimate the TRN for the growth rate of three loggerhead nesting populations (Fuentes et al., 2017; Girondot and Kaska, 2014a; Monsinjon et al., 2017b). The components form a thermodynamic description of the effect of temperature on the rate of biological reactions applied to a Gompertz model for the growth of an embryo (Girondot and Kaska, 2014a). Here, we applied this method following recent upgrades (Girondot et al., 2018). The model requires (i) temperature time series recorded within nests from the moment when eggs were laid to the moment when hatchlings emerged from the nest and (ii) measurements of the Straight Carapace Length (SCL) of hatchlings (SCL data used to infer TRNs are summarized in Supplementary material Table A5).

To detect potential differences in TRNs for growth rate among nesting populations from the same Regional Management Unit (RMU), we applied a similar approach as per Monsinjon et al. (2017b). Briefly, the TRN for growth rate was estimated for two populations 
(i) independently for both populations (hypothesis 1: the populations exhibit different TRNs) and (ii) after data sets of nest temperature were grouped together (hypothesis 2: the populations exhibit similar TRNs). We calculated the Akaike Information Criterion corrected for finite sample size (AICc) and the Akaike weight, i.e. the relative support of both hypotheses (Burnham and Anderson, 2002). The sum of AICc of each model estimated independently (hypothesis 1) were then compared with the AICc of the model estimated with both data sets grouped together (hypothesis 2). Before comparing the populations closest to one another within the same RMU, we first grouped those which belonged to the same "subdivided" management unit (i.e., demographically isolated but not genetically different) (Shamblin et al., 2014). The model selection procedure is presented in Supplementary material Table A6.

Once population-specific TRNs for growth rate were estimated (Supplementary material Note A2, Figure A2), we modeled embryonic development at nesting sites based on long-term time series of reconstructed nest temperatures (NT). If we consider a nest being laid at a date $\mathrm{i}$, the progression of embryo size (SCL) is modeled until it reaches, at the date $\mathrm{i}+\mathrm{n}$, the final SCL of a completely developed embryo (i.e., a freshly emerged hatchling) known for the nesting population. This allowed the extraction of information such as the incubation duration (n), the nest temperature within the whole incubation period, and the nest temperature within the TSP (see section "Estimating sex ratio" for defining TSP boundaries within incubation). The model was run again at the date $i+1$ and so on for the period when NT

296 is available (i.e., each day between 1979 and 2016).

\section{Estimating hatching success}

Here, we introduce a new mathematical description of the thermal tolerances of sea turtle embryos. This model is fitted here for the loggerhead sea turtle using data obtained at constant temperatures in laboratory conditions. The Thermal Tolerance Curve (TTC) is described by a 
model composed of the product of two logistic equations and a term defining the average hatching success within the optimal range of temperatures (equation 1):

$H S=\frac{1}{1+\exp \left(\frac{1}{\left|S_{L}\right|}\left(P_{L}-t\right)\right)} \times \frac{1}{1+\exp \left(\frac{1}{-\left|S_{H}\right|}\left(P_{H}-t\right)\right)} \times H \quad$ equation 1

With $S_{L}$ and $P_{L}$ being the logistic parameters defining the lower part of the curve, $S_{H}$ and $P_{H}$ being the logistic parameters defining the higher part of the curve and $H$ being the average hatching success within the optimal range of temperatures. This method accounts for both the upper and the lower thermal limits for embryo survival, which is a prerequisite when making projections according to extremes scenarios of thermal changes.

To infer the TTC, we used data for the loggerhead sea turtle from five Regional Management Units (RMUs) (Supplementary material Table A7). For each constant temperature experiment, the hatching success is calculated as being the number of embryos that successfully hatched divided by the total number of eggs (of which we subtracted the number of undeveloped embryo if specified in the original publication). The model is fitted using maximum likelihood with a binomial distribution for error. As most of the data come from different populations, we assessed potential similarities among RMUs. To detect potential differences, we estimated the TTCs (i) independently (making the hypothesis that RMUs exhibit different TTCs) and (ii) after all data were grouped together (making the hypothesis that RMUs exhibit similar TTCs). Based on the AICc and the Akaike weight, TTCs were found similar among RMUs (Supplementary material Note A3).

The model described here allows for predicting the hatching success for any nest that incubated at constant temperatures (Supplementary material Figure A3). However, temperature is not constant under natural conditions and it is poorly known how fluctuating thermal regimes influence hatching success (Howard et al., 2014). Using published data of 
hatching success from natural nests (Godley et al., 2001; Horne et al., 2014; Read et al., 2013), we searched for an equivalent at constant temperature (i.e., the mean nest temperature during incubation plus a correction parameter) that best describes hatching success in natural conditions. This correction parameter aims to adjust data from natural conditions so they can be compared with data from constant temperature experiments. Data were extracted from figures in respective original publications using the software WebPlotDigitizer version 4.1 (https://automeris.io/WebPlotDigitizer/) when tables were not provided. We predicted the hatching success from mean nest temperatures with a correction parameter varying from $1.5^{\circ} \mathrm{C}$ to $+1.5^{\circ} \mathrm{C}$ each $0.01^{\circ} \mathrm{C}$ and we kept the value that minimizes the dispersion (sum of squares) of residuals (here $+0.32^{\circ} \mathrm{C}$, see Supplementary material Note A3).

\section{Estimating sex ratio}

The loggerhead sea turtle exhibits a cool male/warm female pattern of Temperaturedependent Sex Determination (TSD) (Yntema and Mrosovsky, 1980). We inferred the Thermal Reaction Norm (TRN) for sex ratio of loggerhead populations nesting in Mediterranean, Northwest Atlantic, Southwest Atlantic and Southwest Indian Regional Management Units (RMUs) based on constant temperature experiments previously carried out in laboratory conditions. Data for Mediterranean were from Greece (Mrosovsky et al., 2002). Data for Northwest Atlantic were from Florida (Mrosovsky, 1988), North Carolina (Mrosovsky, 1988) and Georgia (Yntema and Mrosovsky, 1980, 1982). Data for Southwest Atlantic were from Brazil (Marcovaldi et al., 1997). Data for Southwest Indian ocean were from South Africa (Maxwell, 1987). We estimated TRNs for sex ratio using a logistic equation (Girondot, 1999).

The simple mean temperature during either periods of incubation typically is a poor predictor of sex ratio because the effect of temperature on sex determination may vary with gonadal growth which also depends on temperature (Georges et al., 2005; Neuwald and 
Valenzuela, 2011). A Constant Temperature Equivalent (CTE) was developed to account for such effect by calculating the temperature at which half of the development occurred (Georges, 1989; Georges et al., 1994). Here, we used a recent update that accounts for a nonlinear development within incubation (Fuentes et al., 2017). Basically, this CTE is the mean temperature weighted by the differential growth within the TSP. We produced sex ratio estimates based on population-specific TRNs for sex ratio (Supplementary material Note A4, Figure A4) using this proxy.

The ThermoSensitive Period (TSP) of development occurs between embryonic stages 21 and 26 for sea turtles (Miller, 1985) which roughly corresponds to the middle third of incubation at constant temperature as generally observed in most reptiles with TSD (Bull, 1987; Desvages et al., 1993; Girondot et al., 2018; Pieau and Dorizzi, 1981; Woolgar et al., 2013). The Straight Carapace Length (SCL) at the onset of the TSP and the SCL at the end of the TSP are respectively $21 \%$ and $71 \%$ of the SCL of a completely developed embryo for the loggerhead sea turtle (Girondot et al., 2018).

\section{Unraveling the dynamics of nesting activity}

We used a set of equations that describe the underlying dynamics of a nesting season based on time series of nest counts (Girondot, 2017). Basically, a nonlinear function with seven parameters was fitted using maximum likelihood with negative-binomial distribution for each ordinal day of the year. These parameters describe adequately the pattern of a nesting season: a minimum number of nests when turtles are not active before and after the active season and a maximum number of nests at the ordinal day when the peak of activity occurs around which the curve can flatten out. The dispersion around the mean was controlled by a negativebinomial parameter (Girondot, 2017). Here we assumed that the curve was not flat around the peak because a visual examination of nest counts showed a bell-shaped distribution. First, we allowed all parameters to vary across seasons to obtain a "season-specific" description of 
nesting activity at any nesting site. Second, we fitted parameters without allowing them to vary across seasons to obtain a "global" description of nesting activity. The global description of nesting activity was used in Figure 4 to provide a visual picture of the dynamics of nesting activity along with within-year variations in hatching success and sex ratio. The seasonspecific description of nesting activity was used to capture the actual interseasonal variability of current hatching success and sex ratio indices while the global description of nesting activity was used to project future indices, assuming the overall pattern of nesting seasons will remain unchanged until 2100.

\section{Calculating hatching success and sex ratio indices}

We calculated a Hatching Success Index (HSI) as being the average hatching success during a nesting season weighted by the number of nests laid (equation 2).

$$
H S I=\frac{\sum_{i=k}^{N} H S_{i} \times N e s t_{i}}{\sum_{i=k}^{N} \text { Nest }_{i}} \quad \text { equation } 2
$$

$H S_{i}$ is the hatching success (survival proportion) for nests laid at the day $i$ of the season with $k$ being the first date of the season. Nest $t_{i}$ is the number of nests laid at the day $i$ of the season. $N$ is the last date of the season.

We calculated a Sex Ratio Index (SRI) as being the average sex ratio during a nesting season corrected by the hatching success and weighted by the number of nests laid, which is the sex ratio of surviving hatchlings (equation 3).

$S R I=\frac{\sum_{i=k}^{N} S R_{i} \times N e s t_{i} \times H S_{i}}{\sum_{i=k}^{N} N^{2} s t_{i} \times H S_{i}} \quad$ equation 3

$S R_{i}$ is the sex ratio (male proportion) for nests laid at the day $i$ of the season with $k$ being the first date of the season. Nest $t_{i}$ is the number of nests laid at the day $i$ of the season. $H S_{i}$ is the hatching success for nests laid at the day $i$ of the season. $N$ is the last date of the season. 
were surveyed (see Supplementary material Table A2) and using the season-specific description of nesting activity. Future indices (i.e., forecasts for the 2062-2100 period) were calculated for all future seasons $(n=38)$ using the global description of nesting activity (see section "Unraveling the dynamics of nesting activity" for the descriptions of nesting activity).

RESULTS

\section{Current nesting activity, hatching success and sex ratio}

404

405

Currently, the nesting seasons occur when the hatching success is optimal at Dalyan Beach, Blackbeard Island, Wassaw Island, Rio de Janeiro, and Bhanga Nek (respectively, Figure 4a, b, c, f and g). A different situation is observed at Boca Raton and Praia do Forte, where the hatching success decreases slightly around the peak of nesting (respectively, Figure $4 \mathrm{~d}$ and e).

The nesting seasons occur when both sexes are produced in variable proportions (with a peak of nesting when mostly female hatchlings are expected) at Dalyan Beach, Blackbeard Island, Wassaw Island, Rio de Janeiro, and Bhanga Nek (respectively, Figure 4h, i, j, m and n). A different situation is observed at Boca Raton and Praia do Forte, where the whole nesting seasons occur when a nearly $100 \%$ female-biased sex ratio is expected (respectively, Figure 4k and 1).

\section{Warming temperatures may reduce hatching success and induce a feminization of}

\section{hatchlings}

Current Hatching Success Indices (HSIs) are optimal for all nesting populations studied here except at Boca Raton and Praia do Forte (Figure 5a). Under an optimistic warming scenario (RCP4.5), all nesting populations are expected to face a reduction in hatching success, except 
at Dalyan Beach (Figure 5a). According to this scenario, the population nesting at Boca Raton should face a very low hatching success $(<20 \%)$. Under a pessimistic warming scenario (RCP 8.5), all nesting populations should face a hatching success lower than 50\%, except at Dalyan Beach (Figure 5a). In this extreme warming situation, expected phenological shifts can effectively buffer reductions in hatching success, except for populations nesting at Boca Raton and Praia do Forte which may face a very low hatching success $(<10 \%)$ either ways (Figure 5a). Raton ( $>95 \%$ females) whereas it is less skewed toward females at other nesting sites $(<85 \%$ females) (Figure 5b). Under an optimistic warming scenario (RCP4.5), the sex ratio might become increasingly female-biased in all nesting populations studied here (with only female hatchlings expected at Praia do Forte), except at Boca Raton where the proportion of males is expected to increase slightly (Figure 5b). Under a pessimistic warming scenario (RCP8.5), all nesting populations should experience a highly female-biased sex ratio ( $>95 \%$ females), except at Boca Raton where the proportion of males might increase substantially (Figure 5b).

In both warming situations, only the population nesting at Dalyan Beach may benefit from a buffering effect of expected phenological shifts while the opposite situation is observed at Boca Raton (Figure 5b).

\section{Most populations could face a climatic debt in the future}

Phenological shifts required in the future (2062-2100 as compared to 1979-2016) for HSIs and SRIs to remain within current ranges (i.e., climatic prices) range from 0 day earlier (for HSI at Dalyan Beach under an optimistic warming scenario: RCP4.5) to 118 days earlier (for HSI at Rio de Janeiro under a pessimistic warming scenario: RCP8.5) (Table 1, 442 Supplementary material Figure A5). Six out of the seven nesting populations studied here could face a climatic debt in the future under both warming scenarios and for both the HSI 
and the SRI (Table 1). Only the population nesting at Dalyan Beach might not face a climatic debt in the future for the HSI to remain within its current range and only under the RCP4.5 scenario (Table 1).

\section{DISCUSSION}

For ectotherms, such as fishes, amphibians and non-avian reptiles, temperature is a major driver of population distribution and viability (Angilletta et al., 2010; Deutsch et al., 2008; Huey et al., 2009; Maffucci et al., 2016). Our results highlight differences among loggerhead nesting populations in their capacity to keep pace with the rate of thermal changes and suggest that only a subset of populations may be able to offset detrimental effects by shifting their nesting phenology. A growing number of studies have suggested that phenological changes may, to some extent, buffer detrimental effects of warming temperatures on reptile embryos (Almpanidou et al., 2018; Mitchell et al., 2008; Mitchell et al., 2016; Stubbs et al., 2014). For many sea turtle populations, whether climate-induced phenological shifts confer the potential to buffer detrimental effects on their progeny remains unclear. Here we took a step forward in the prediction of warming impacts on sea turtles' hatching success and sex ratio using an elaborate modeling approach and comparing distant populations, which should inform new strategies for prioritizing conservation efforts at a global scale. Importantly, our model offers a process-based framework to quantify the sex ratio of sea turtle hatchlings during a nesting season by considering (i) the number of nests laid and (ii) the proportion of surviving embryos under both cold and warm conditions.

\section{Nesting activity, hatching success and sex ratio}

Loggerhead populations nesting at the lowest latitudes of our data sets (Boca Raton, Florida, and Praia do Forte, Brazil) are already at the edge of thermal limits for embryo survival 
(Figure $4 \mathrm{~d}$ and e) and nest during the period when mostly female hatchlings are produced.

469 Conversely, other populations studied here, which nest at relatively higher latitudes, may experience optimal incubation temperatures for embryo survival and produce a more balanced sex ratio. Overall, male hatchlings are more likely to hatch during the first part of the nesting season while mostly females are produced during the rest of the nesting season. This may explain why future sex ratio at Boca Raton is expected to be less skewed toward females, because remaining male-producing clutches would experience more suitable temperatures at the beginning of the nesting season than middle and late clutches that may experience $100 \%$ failure, as currently suspected at female-producing nesting sites (Figure $4 \mathrm{~d}$ and e).

Whether a highly female-biased primary sex ratio is likely to persist through age classes may vary within and among sea turtle species (Hamann et al., 2013; Hamann et al., 2010). If feminization of the primary sex ratio persists in the adult sex ratio, detrimental effects at population level can occur such as (i) reduced fertility rates (Bell et al., 2009) and/or (ii) loss of genetic diversity through reduction of effective population size (Hamann et al., 2010). Concerning these threats, males can breed annually with multiple females while females do not breed every year. This sex-specific difference in reproductive behavior can be somewhat compensatory and balance the operational sex ratio, thus buffering current or future negative effects of female-biased adult sex ratios on fertility rates (Hays et al., 2010; Wright et al., 2012). According to some authors, temperature-dependent sex determination can confer a short-term demographic advantage by producing more females at increasing temperatures, which could first enhance population growth (Hays et al., 2017). However, such a positive effect on population dynamics does not seem sufficient to offset the current rate of climatic changes in the long term (Laloë et al., 2014, 2017; Saba et al., 2012; Santidrián Tomillo et al., 2015a). A decrease in effective population size finally seems inevitable, which in turn can induce genetic erosion and thus lower potential to respond to selection pressures (Hamann et 
al., 2010). There is a strong need for further research into population dynamics, and particularly modeling, that integrates genetic Allee effects linked to potential biases in sex ratio (Mitchell et al., 2010).

Nesting phenology and hatching success both influence the number of male and female hatchlings that may reach the sea. Only a few studies have attempted to account for differential survival of both sexes accounting for temperature-mediated hatching success or emergence rate (Hays et al., 2017; Santidrián Tomillo et al., 2014) and none have accounted for the number of nests before the present study. Here we provide reliable quantitative predictions of temperature-mediated hatching success based on the thermal tolerance curve of loggerhead embryos, which accounts for both lower and upper critical limits. This novel model should now be calibrated in other sea turtle species to make accurate predictions under both cold and warm extreme conditions, which is particularly relevant for populations nesting at high latitudes where seasons are more pronounced. Nevertheless, this method can still be improved. In natural conditions, embryo survival depends on the magnitude of the thermal stress and the time spent over a critical threshold (Howard et al., 2014, 2015). Therefore, new methods to predict hatching success should be deployed to capture biologically-determined thermal variation. Recent studies about heat tolerance of loggerhead embryos will probably help in refining models that incorporated cellular processes underlying embryo survival in response to temperature (Bentley et al., 2017; Tedeschi et al., 2016). Precipitations and moisture levels within nests are other factors that influence hatching success, either directly or

513 indirectly through an evaporative cooling effect (Montero et al., 2018a; Montero et al., 2018b;

514 Pike, 2013; Santidrián Tomillo et al., 2015b). Further studies must integrate this parameter

515 into a more comprehensive model to forecast the hatching success of sea turtles as the rate of 516 precipitation is also expected to change in the future (IPCC, 2014).

\section{Phenological shifts: adaptive potential and implications for conservation}


518 Sea turtles have been around for more than 110 million years (Hirayama, 1998) and have

519 survived dramatic thermal changes (Hamann et al., 2007; Hawkes et al., 2009). However, the mechanisms by which sea turtles adapted and whether they will be able to adapt in the future remains an open question. Shifting the nesting season is one key response to rising environmental temperatures. In a freshwater turtle, it appears that shifting the nesting season may not be effective enough to offset warming impacts on sex ratio (Schwanz and Janzen, 2008; Telemeco et al., 2013). The opposite conclusion reached for tuataras (Nelson et al., 2018). Our results highlight differences in the efficiency of phenological shifts among loggerhead populations to buffer detrimental effects of warming temperatures, with populations nesting at the edge of lethal thermal limits being likely at greater risks (i.e., low hatching success and female-biased sex ratio). Following this, several management strategies can be proposed: (i) nest relocation, artificial nest shading and watering to cool the nests (Esteban et al., 2018; Hill et al., 2015), (ii) preservation, restoration and enrichment of native coastal vegetation to increase available shaded areas (Kamel, 2013), (iii) assisted migration (or colonization) of nesting sites by moving eggs to colder beaches (Bowen et al., 1994a) and (iv) foster international collaborations and agreements for safeguarding sea turtles worldwide

534 (Carr, 1956; Wold, 2002) to allow for a better protection of resilient nesting populations, like the one nesting at Dalyan Beach, Turkey, identified in the present study. The first strategy requires long-term human resources, which are not always available depending on the country. Moreover, this strategy could slow down or prevent potential local adaptations by 538 lowering natural selection pressures (Mrosovsky, 2006). The second strategy could be 539 sustainable but further research is needed to anticipate potential detrimental effects of highly 540 vegetated beaches on egg incubation and female nesting success (Wood et al., 2014). The 541 third strategy, here based on sea turtles' natal homing behavior, is still controversial and 542 requires, among others, an extensive ecological understanding of the species and a careful 
characterization of new intended habitats (Dade et al., 2014; McLachlan et al., 2007). We urge further research to evaluate the risks and benefits associated with assisted migration and we recommend following the last proposed strategy, while further identifying other resilient nesting populations and potentially suitable beaches for nesting based on the application and development of our approach.

Here we assumed that $1^{\circ} \mathrm{C}$ increase in sea surface temperature will shift nesting seasons 7 days earlier (Weishampel et al., 2004). However, this relationship could vary among populations and whether temperature affects nesting phenology at foraging, breeding, and/or nesting areas remains unclear (Mazaris et al., 2009; Monsinjon et al., 2019). One of the steepest responses was found in Mediterranean where loggerheads start nesting 8.5 days earlier in response to $1^{\circ} \mathrm{C}$ increase in sea surface temperature at breeding areas (Mazaris et al., 2008). Conversely, the slope of this relationship seems to be weaker for populations nesting at low latitudes (Mazaris et al., 2013), which may jeopardize even more their ability to adapt to rising temperatures. Moreover, we do not know whether the general pattern of nesting activity will remain the same in the future. There is limited advancement of nesting phenology in some loggerhead populations but no evidence for delayed initiation of nesting in response to warmer temperatures, as observed in leatherback sea turtles (Dermochelys coriacea) (Neeman et al., 2015). Some loggerhead populations have shortened their nesting season in response to warmer temperatures (Pike et al., 2006; Weishampel et al., 2010) while the opposite response was also found in other populations (Hawkes et al., 2007; Lamont and Fujisaki, 2014). Better understanding of the timing of sea turtle reproduction is a gap that needs further research.

\section{Thermal heterogeneity, spatial shifts and other threats}

In the present study, we reproduced thermal heterogeneity at a fine temporal and geographical scale through modeling, but we did not account for thermal heterogeneity occurring at other spatial scales: inside a nest and between nests of the same nesting beach. Within a nesting 
beach, in the context of global warming, eggs developing at cooler temperatures could suffer

569 less mortality than those developing at warmer temperatures, such that our model could underestimate the proportion of male hatchlings. Further studies are required to provide biologically-relevant characterization of thermal heterogeneity at these finer spatial scales.

572 Here, we projected nest temperatures based on a correlative model that involves air 573 temperature and sea surface temperature. Nevertheless, the temperature within a nest depends 574 on soil properties (e.g., thermal conductivity, soil reflectance) and other external forcing (e.g., wind speed, solar radiation, water content) that must be considered. Much effort is warranted for assessing the environmental conditions at nesting sites and the physical properties of beaches to better predict nest temperatures, possibly using a (mechanistic) microclimate 578 model (Fuentes and Porter, 2013; Kearney and Porter, 2017; Mitchell et al., 2016; Porter et 579 al., 2010).

Such micro-environmental variability may provide reptiles with a way for buffering the effects of climate change. Females might modify the placement of their nests in order to compensate for rising temperatures (Doody et al., 2006; Doody and Moore, 2010). For instance, shade cover may provide sufficient thermal variation for a freshwater turtle to select thermal microhabitats for nesting (Refsnider et al., 2013). Variation in sand color at nesting beaches can also provide thermal microhabitats (Hays et al., 2001). This adaptive mechanism may be effective as long as nesting sites with different available thermal conditions remain accessible (Doody and Moore, 2010; Refsnider and Janzen, 2012).

Rapid spatial shift of nesting sites at a regional scale is unlikely for sea turtles due to their natal homing behavior and, for some species, high degree of nest site fidelity (reviewed in Miller, 1997). However, a few loggerhead females were found to attempt nesting hundreds of kilometers distant from their former nesting sites in Australia (Limpus, 2008) and tens of

592 kilometers in South Africa (Nel et al., 2013). These wanderers have the potential to forge 
range extensions. Establishment of new nesting sites may compensate the loss of current nesting sites (Fuentes et al., 2013; Hawkes et al., 2009), provided that other suitable nesting beaches are still available (Katselidis et al., 2012; Pike, 2013). For example, the population nesting at Bhanga Nek, South Africa, may benefit from the availability of suitable nesting beaches farther South along the East coast of Africa which provides sandy beaches within a wide range of latitudes.

In any case, other environmental changes will soon threaten or are already threatening the viability of sea turtles populations: (i) the availability of nesting sites may decrease as the sea level rises (Fuentes et al., 2010), (ii) coastal development may further disturb these nesting habitats (Fuentes et al., 2016; Sella and Fuentes, 2019), (iii) changes in precipitation regimes may affect incubation success and hatchling sex ratio (Montero et al., 2019; Santidrián Tomillo et al., 2015b), (iv) increasing intensity of extreme climatic events may cause a high number of nest destruction (Fuentes and Abbs, 2010), and finally (v) adults can be affected by other threats such as bycatch in fisheries and pollution (Hawkes et al., 2009; Patrício et al., 2018).

\section{Conclusions}

By assessing the adaptive potential of phenological shifts under two plausible warming scenarios, our study enabled the identification of loggerhead nesting populations that might face detrimental thermal conditions at nesting beaches in the future. Within the locations studied, we found that the population nesting at Dalyan Beach, Turkey, will be able to keep track of suitable thermal conditions under an optimistic scenario of future changes in environmental temperatures. Under a pessimistic warming scenario, only this population nesting at Dalyan Beach would be able to buffer, but not utterly offset, the effect of warming temperatures. We also identified two populations that might experience low embryo survival and mostly females being produced under both warming scenarios, which are those nesting at 
618 Boca Raton, Florida, and Praia do Forte, Brazil. These results show the importance of modeling the long-term site-specific effects of climate change at a local scale to be able to evaluate the sustainability of diverse populations. Other sea turtle species already face or will soon face such warming impacts at their nesting sites and thus warrant further investigations.

The use and development of our approach should prove useful for assessing the viability of sea turtle populations as well as other ectotherms. Combining thermal tolerances, physiological and phenological processes, our conceptual approach can be applied to other ectotherm species spatially-constrained by their natal homing behavior and their high degree of nest site fidelity, such as salmon and other anadromous fish species, to explore the potential of phenological shifts in thermal niche tracking. Species can adapt to environmental changes by shifting their spatial and temporal distribution (i.e., habitat range and phenological shifts, respectively) simultaneously (Chuine, 2010), so that phenological shifts can buffer or neutralize range shifts (Socolar et al., 2017). Future research should now combine resourcedriven and climate-driven shifts in phenology and geography in a single framework to explore the adaptive potential of species in response to contemporary climate change.

\section{ACKNOWLEDGEMENTS}

J.M. and M.G. acknowledge the support of the Virtual Data initiative, run by LABEX P2IO and supported by Université Paris-Sud, for providing computing resources on its cloud infrastructure. A-M.L., K.W. and D.R. appreciate the ability to conduct research through cooperation from the US Fish and Wildlife Service, Savannah Coastal Refuges and especially thank M. Frick, T. Wibbels, D. Barnard-Keinath, J. Robinette, and P. Range as well as people 640 from the Caretta Research Project. M.L., P.L., A.S., M.A.G.d.M. and M.M.P.B.F thank TAMAR's staff for all the support and to who helped collect field data. J.W. and K.R. 
642 acknowledge the help from L. Bachler, K. Blair, L. Celano, S. Ceriani, C. Gonzales, A. 643 Lolavar, M. Rogers, J. Vaughan, N. Warraich, N. Tempel, M. Koperski, S. McPherson, R. 644 Trindell, B. Witherington, and the support from many organizations including Gumbo Limbo 645 Nature Center, Loggerhead Marinelife Center, Mote Marine Lab, Quantum Associates (FPL), 646 Sanibel-Captiva Sea Turtle Program, UCF Marine Turtle Program, and Palm Beach County 647 DERM.

\section{FUNDING}

650

Funding for data collection in South Africa was provided by National Research Foundation

651 (Thuthuka Program). Funding for data collection in Florida was provided by EPA STAR 652 grant GAD R82- 9094, NMFS funds, support from the National Save the Sea Turtle Foundation, Devocean.com, the Nelligan Sea Turtle Fund, and J.W. personal funds.

654

\section{AUTHOR CONTRIBUTIONS}

656

J.M. initiated the project and performed the data analysis. J.W., K.R., M.L., P.L., A.S., 657 M.A.G.d.M., M.M.P.B.F, Y.K., J.T., R.N., K.L.W., A.-M.L. and D.R. compiled the data. J.M and J.-M.G. conceived the manuscript. M.G. built mathematical models. J.M. wrote the manuscript with contributions from all authors.

660

662 The authors declare no competing interests. 
Data collection at Bhanga Nek took place under the Research Agreement with iSimangalio

666

667

668

669

670

671

672

673

674

675

676

677

678

679

680

681

682

683

684

685

686

Wetland Authority, with animal ethics clearance (A09-SCI-ZOO-005) and Dept of Environmental Affairs Permits (RES2010/55 \& 2011/41). Data collection in Georgia was conducted under Georgia DNR permit Nos. 29-WMB-03-157 and 29-WMB-04-136; USFWS permit No. 41620-02018; and approved by the Georgia Southern University IACUC. Data collection in Florida was conducted under FAU IACUC approval, Florida Sea Turtle permit 073, and USFWS permits.

\section{SUPPLEMENTARY MATERIAL}

Supplementary material includes four notes, five figures and seven tables and can be found with this article online. Correspondence and requests for materials should be addressed to M.G. Statistical analyses were performed using R (R Core Team, 2019). Mathematical models used in this study are available in the following R packages: 'phenology' (Girondot, 2019b) and 'embryogrowth' (Girondot, 2019a).

\section{REFERENCES}

Almpanidou, V., Katragkou, E., Mazaris, A.D., 2018. The efficiency of phenological shifts as an adaptive response against climate change: a case study of loggerhead sea turtles (Caretta caretta) in the Mediterranean. Mitigation and Adaptation Strategies for Global Change 23, 1143-1158.

Angilletta, M.J., Huey, R.B., Frazier, M.R., 2010. Thermodynamic effects on organismal performance: is hotter better? Physiological and Biochemical Zoology 83, 197-206. 
687

688

689

690

691

692

693

694

695

696

697

698

699

700

701

702

703

704

705

706

707

708

709

710

Bell, C.D., Blumenthal, J.M., Broderick, A.C., Godley, B.J., 2009. Investigating potential for depensation in marine turtles: How low can you go? Conservation Biology.

Bellard, C., Bertelsmeier, C., Leadley, P., Thuiller, W., Courchamp, F., 2012. Impacts of climate change on the future of biodiversity. Ecology Letters 15, 365-377.

Bentley, B.P., Haas, B.J., Tedeschi, J.N., Berry, O., 2017. Loggerhead sea turtle embryos

(Caretta caretta) regulate expression of stress response and developmental genes when exposed to a biologically realistic heat stress. Molecular Ecology 26, 2978-2992.

Booth, D.T., Astill, K., 2001. Temperature variation within and between nests of the green sea turtle, Chelonia mydas (Chelonia: Cheloniidae) on Heron Island, Great Barrier Reef.

Australian Journal of Zoology 49, 71-84.

Bowen, B.W., Conant, T.A., Hopkins-Murphy, S.R., 1994a. Where are they now? The Kemp's ridley headstart project. Conservation Biology 8, 853-856.

Bowen, B.W., Kamezaki, N., Limpus, C.J., Hughes, G.R., Meylan, A.B., Avise, J.C., 1994b.

Global phylogeography of the loggerhead turtle (Caretta caretta) as indicated by mitochondrial DNA haplotypes. Evolution 48, 1820-1828.

Bowen, B.W., Karl, S.A., 2007. Population genetics and phylogeography of sea turtles. Molecular Ecology 16, 4886-4907.

Bradshaw, W.E., Holzapfel, C.M., 2006. Evolutionary response to rapid climate change. Science 312, 1477-1478.

Broderick, A.C., Godley, B.J., Hays, G.C., 2001. Metabolic heating and the prediction of sex ratios for green turtles (Chelonia mydas). Physiological and Biochemical Zoology 74, 161170.

Bull, J.J., 1987. Temperature-sensitive periods of sex determination in a lizard: similarities with turtles and crocodilians. Journal of Experimental Zoology 241, 143-148. 
Bull, J.J., Vogt, R.C., Bulmer, M.G., 1982. Heritability of sex ratio in turtles with

712 environmental sex determination. Evolution 36, 333-341.

713 information-theoretic approach. Springer-Verlag, New York. Shores. The University of Florida Press. Science 320, 800-803. of the Royal Society B: Biological Sciences 365, 3149-3160. Nature 388, 526. Animal Conservation 17, 4-17.

Burnham, K.P., Anderson, D.R., 2002. Model selection and multimodel inference: A practical

Carr, A., 1956. The Windward Road: Adventures of a Naturalist on Remote Caribbean

Charmantier, A., McCleery, R.H., Cole, L.R., Perrins, C., Kruuk, L.E., Sheldon, B.C., 2008. Adaptive phenotypic plasticity in response to climate change in a wild bird population.

Chevin, L.M., Lande, R., Mace, G.M., 2010. Adaptation, plasticity, and extinction in a changing environment: towards a predictive theory. PloS Biology 8, e1000357.

Chuine, I., 2010. Why does phenology drive species distribution? Philosophical Transactions

Crick, H.Q.P., Dudley, C., Glue, D.E., Thomson, D.L., 1997. UK birds are laying eggs earlier.

Dade, M.C., Pauli, N., Mitchell, N.J., 2014. Mapping a new future: using spatial multiple criteria analysis to identify novel habitats for assisted colonization of endangered species.

Dee, D.P., Uppala, S.M., Simmons, A.J., Berrisford, P., Poli, P., Kobayashi, S., Andrae, U., Balmaseda, M.A., Balsamo, G., Bauer, P., Bechtold, P., Beljaars, A.C.M., van de Berg, L., Bidlot, J., Bormann, N., Delsol, C., Dragani, R., Fuentes, M., Geer, A.J., Haimberger, L., Healy, S.B., Hersbach, H., Hólm, E.V., Isaksen, L., Kållberg, P., Köhler, M., Matricardi, M., McNally, A.P., Monge-Sanz, B.M., Morcrette, J.-J., Park, B.-K., Peubey, C., de Rosnay, P., Tavolato, C., Thépaut, J.-N., Vitart, F., 2011. The ERA-Interim reanalysis: configuration and 
performance of the data assimilation system. Quarterly Journal of the Royal Meteorological Society $137,553-597$.

Desvages, G., Girondot, M., Pieau, C., 1993. Sensitive stages for the effects of temperature on gonadal aromatase activity in embryos of the marine turtle Dermochelys coriacea. General and Comparative Endocrinology 92, 54-61.

Deutsch, C.A., Tewksbury, J.J., Huey, R.B., Sheldon, K.S., Ghalambor, C.K., Haak, D.C., Martin, P.R., 2008. Impacts of climate warming on terrestrial ectotherms across latitude. Proceedings of the National Academy of Sciences 105, 6668-6672.

Devictor, V., Swaay, C.v., Brereton, T., Brotons, L., Chamberlain, D., Heliölä, J., Herrando, S., Julliard, R., Kuussaari, M., Lindström, Å., Reif, J., Roy, D.B., Schweiger, O., Settele, J., Stefanescu, C., Strien, A.V., Turnhout, C.V., Vermouzek, Z., WallisDeVries, M., Wynhoff, I., Jiguet, F., 2012. Differences in the climatic debts of birds and butterflies at a continental scale. Nature Climate Change 2, 121-124.

Doody, J.S., Guarino, E., Georges, A., Corey, B., Murray, G., Ewert, M., 2006. Nest site choice compensates for climate effects on sex ratios in a lizard with environmental sex determination. Evolutionary Ecology 20, 307-330.

Doody, J.S., Moore, J.A., 2010. Conceptual Model for thermal limits on the distribution of Reptiles. Herpetological Conservation and Biology 5, 283-289.

Eccel, E., 2010. What we can ask to hourly temperature recording. Part 1: Statistical vs. meteorological meaning of minimum temperature. Italian Journal of Agrometeorology XV, $41-43$.

Esteban, N., Laloë, J.-O., Kiggen, F.S.P.L., Ubels, S.M., Becking, L.E., Meesters, E.H., Berkel, J., Hays, G.C., Christianen, M.J.A., 2018. Optimism for mitigation of climate warming impacts for sea turtles through nest shading and relocation. Scientific Reports 8, 17625. 
Fuentes, M.M.P.B., Abbs, D., 2010. Effects of projected changes in tropical cyclone frequency on sea turtles. Marine Ecology Progress Series 412, 283-292.

Fuentes, M.M.P.B., Gredzens, C., Bateman, B.L., Boettcher, R., Ceriani, S.A., Godfrey, M.H., Helmers, D., Ingram, D.K., Kamrowski, R.L., Pate, M.P., Pressey, R.L., Radeloff, V.C., 2016. Conservation hotspots for marine turtle nesting in the United States based on coastal development. Ecological Applications 26, 2706-2717.

Fuentes, M.M.P.B., Limpus, C., Hamann, M., 2011. Vulnerability of sea turtle nesting grounds to climate change. Global Change Biology 17, 140-153.

Fuentes, M.M.P.B., Limpus, C.J., Hamann, M., Dawson, J., 2010. Potential impacts of projected sea level rise to sea turtle rookeries. Aquatic conservation: marine and freshwater ecosystems 20, 132-139.

Fuentes, M.M.P.B., Monsinjon, J., Lopez, M., Lara, P., Santos, A., Marcovaldi, M.A.G.d., Girondot, M., 2017. Sex ratio estimates for species with temperature-dependent sex determination differ according to the proxy used. Ecological Modelling 365, 55-67. Fuentes, M.M.P.B., Pike, D.A., Dimatteo, A., Wallace, B.P., 2013. Resilience of marine turtle regional management units to climate change. Global Change Biology 19, 1399-1406. Fuentes, M.M.P.B., Porter, W.P., 2013. Using a microclimate model to evaluate impacts of climate change on sea turtles. Ecological Modelling 251, 150-157.

Georges, A., 1989. Female turtles from hot nests: Is it duration of incubation or proportion of development at high temperatures that matters? Oecologia 81, 323-328.

Georges, A., 2013. For reptiles with temperature-dependent sex determination, thermal variability may be as important as thermal averages. Animal Conservation 16, 493-494. Georges, A., Beggs, K., Young, J.E., Doody, J.S., 2005. Modelling development of reptile embryos under fluctuating temperature regimes. Physiological and Biochemical Zoology 78, 18-30. 
Georges, A., Limpus, C.J., Stoutjesdijk, R., 1994. Hatchling sex in the marine turtle Caretta caretta is determined by proportion of development at a temperature, not daily duration of exposure. Journal of Experimental Zoology 270, 432-444.

Girondot, M., 1999. Statistical description of temperature-dependent sex determination using maximum likelihood. Evolutionary Ecology Research 1, 479-486.

Girondot, M., 2017. Optimizing sampling design to infer the number of marine turtles nesting on low and high density sea turtle rookeries using convolution of negative binomial distribution. Ecological Indicators 81, 83-89.

Girondot, M., 2019a. embryogrowth: Tools to analyze the thermal reaction norm of embryo growth, 7.5.9 ed. The Comprehensive R Archive Network, http://www.cran.org.

Girondot, M., 2019b. phenology: Tools to manage a parametric function that describes phenology, 7.3.2 ed. The Comprehensive R Archive Network, http://www.cran.org. Girondot, M., Kaska, Y., 2014a. A model to predict the thermal reaction norm for the embryo growth rate from field data. Journal of Thermal Biology 45, 96-102.

Girondot, M., Kaska, Y., 2014b. Nest temperatures in a loggerhead-nesting beach in Turkey is more determined by sea surface temperature than air temperature. Journal of Thermal Biology 47, 13-18.

Girondot, M., Monsinjon, J., Guillon, J.-M., 2018. Delimitation of the embryonic thermosensitive period for sex determination using an embryo growth model reveals a potential bias for sex ratio prediction in turtles. Journal of Thermal Biology 73, 32-40. Godfrey, M.H., Barreto, R., Mrosovsky, N., 1997. Metabolically-generated heat of developing eggs and its potential effect on sex ratio of sea turtle hatchlings. Journal of Herpetology 31 , 616-619.

Godley, B.J., Broderick, A.C., Downie, J.R., Glen, F., Houghton, J.D., Kirkwood, I., Reece, S., Hays, G.C., 2001. Thermal conditions in nests of loggerhead turtles: Further evidence 
suggesting female skewed sex ratios of hatchling production in the Mediterranean. Journal of Experimental Marine Biology and Ecology 263, 45-63.

Hamann, M., Fuentes, M.M.P.B., Ban, N.C., Mocellin, V.J.L., 2013. Climate Change and Marine Turtles, in: Wyneken, J., Lohmann, K.J., Musick, J.A. (Eds.), The Biology of Sea Turtles. CRC Press, Boca Raton, FL, pp. 353-378.

Hamann, M., Godfrey, M.H., Seminoff, J.A., Arthur, K., Barata, P.C.R., Bjorndal, K.A., Bolten, A.B., Broderick, A.C., Campbell, L.M., Carreras, C., Casale, P., Chaloupka, M., F.Chan, S.K., Coyne, M.S., Crowder, L.B., Diez, C.E., Dutton, P.H., Epperly, S.P., FitzSimmons, N.N., Formia, A., Girondot, M., Hays, G.C., Jiunn, C.I., Kaska, Y., Lewison, R., Mortimer, J.A., Nichols, W.J., Reina, R.D., Shanker, K., Spotila, J.R., Tomás, J., Wallace, B.P., Work, T.M., Zbinden, J., Godley, B.J., 2010. Global research priorities for sea turtles: informing management and conservation in the 21st century. Endangered Species Research $11,245-269$.

Hamann, M., Limpus, C., Read, M., 2007. Vulnerability of marine reptiles in the great barrier reef to climate change. Great Barrier Reef Marine Park Authority and Australian Greenhouse Office, Australia.

Hawkes, L.A., Broderick, A.C., Godfrey, M.H., Godley, B.J., 2007. Investigating the potential impacts of climate change on a marine turtle population. Global Change Biology 13, 923-932.

Hawkes, L.A., Broderick, A.C., Godfrey, M.H., Godley, B.J., 2009. Climate change and marine turtles. Endangered Species Research 7, 137-154.

Hays, G.C., Ashworth, J.S., Barnsley, M.J., Broderick, A.C., Emery, D.R., Godley, B.J., Henwood, A., Jones, E.L., 2001. The importance of sand albedo for the thermal conditions on sea turtle nesting beaches. Oikos 93, 87-94. 
Hays, G.C., Fossette, S., Katselidis, K.A., Schofield, G., Gravenor, M.B., 2010. Breeding periodicity for male sea turtles, operational sex ratios, and implications in the face of climate change. Conservation Biology 24, 1636-1643.

Hays, G.C., Mazaris, A.D., Schofield, G., Laloë, J.-O., 2017. Population viability at extreme sex-ratio skews produced by temperature-dependent sex determination. Proceedings of the Royal Society B-Biological Sciences 284, 20162576.

Hill, J.E., Paladino, F.V., Spotila, J.R., Santidrián Tomillo, P., 2015. Shading and watering as a tool to mitigate the impacts of climate change in sea turtle nests. PLoS One 10, e0129528. Hirayama, R., 1998. Oldest known sea turtle. Nature 392, 705-708.

Horne, C.R., Fuller, W.J., Godley, B.J., Rhodes, K.A., Snape, R., Stokes, K.L., Broderick, A.C., 2014. The effect of thermal variance on the phenotype of marine turtle offspring. Physiological and Biochemical Zoology 87, 796-804.

Howard, R., Bell, I., Pike, D.A., 2014. Thermal tolerances of sea turtle embryos: current understanding and future directions. Endangered Species Research 26, 75-86.

Howard, R., Bell, I., Pike, D.A., 2015. Tropical flatback turtle (Natator depressus) embryos are resilient to the heat of climate change. Journal of Experimental Biology 218, 3330-3335. Huey, R.B., Deutsch, C.A., Tewksbury, J.J., Vitt, L.J., Hertz, P.E., Alvarez Perez, H.J., Garland, T., Jr., 2009. Why tropical forest lizards are vulnerable to climate warming. Proceedings of the Royal Society B-Biological Sciences 276, 1939-1948.

Huey, R.B., Kearney, M.R., Krockenberger, A., Holtum, J.A., Jess, M., Williams, S.E., 2012. Predicting organismal vulnerability to climate warming: roles of behaviour, physiology and adaptation. Philosophical Transactions of the Royal Society B: Biological Sciences 367, 1665-1679. 
Hulin, V., Delmas, V., Girondot, M., Godfrey, M.H., Guillon, J.-M., 2009. Temperaturedependent sex determination and global change: Are some species at greater risk? Oecologia 160, 493-506.

IPCC, 2014. Climate Change 2014: Synthesis Report. Contribution of Working Groups I, II and III to the Fifth Assessment Report of the Intergovernmental Panel on Climate Change. [Core Writing Team, R.K. Pachauri and L.A. Meyer (eds.)]. IPCC, Geneva, Switzerland, $151 \mathrm{pp}$.

IUCN, 2016. The IUCN Red List of Threatened Species. Version 2016-3.

<http://www.iucnredlist.org>. Downloaded on 07 December 2016.

Jensen, M.P., Allen, C.D., Eguchi, T., Bell, I.P., LaCasella, E.L., Hilton, W.A., Hof, C.A.M., Dutton, P.H., 2018. Environmental Warming and Feminization of One of the Largest Sea Turtle Populations in the World. Current Biology 28, 154-159.

Kamel, S.J., 2013. Vegetation cover predicts temperature in nests of the hawksbill sea turtle: implications for beach management and offspring sex ratios. Endangered Species Research $20,41-48$.

Katselidis, K.A., Schofield, G., Stamou, G., Dimopoulos, P., Pantis, J.D., Katzner, T., 2012. Females first? Past, present and future variability in offspring sex ratio at a temperate sea turtle breeding area. Animal Conservation 15, 508-518.

Kearney, M.R., Porter, W.P., 2017. NicheMapR - an R package for biophysical modelling: the microclimate model. Ecography 40, 664-674.

Laloë, J.-O., Cozens, J., Renom, B., Taxonera, A., Hays, G.C., 2014. Effects of rising temperature on the viability of an important sea turtle rookery. Nature Climate Change 4, 513518. 
Laloë, J.-O., Cozens, J., Renom, B., Taxonera, A., Hays, G.C., 2017. Climate change and temperature-linked hatchling mortality at a globally important sea turtle nesting site. Global Change Biology 23, 4922-4931.

Lamont, M.M., Fujisaki, I., 2014. Effects of ocean temperature on nesting phenology and fecundity of the loggerhead sea turtle (Caretta caretta). Journal of Herpetology 48, 98-102. Limpus, C.J., 2008. A Biological Review of Australian Marine Turtle Species. 1. Loggerhead Turtle, Caretta caretta (Linneaus), in: Fein, L. (Ed.). DERM, The State of Queensland, Environmental Protection Agency.

Maffucci, F., Corrado, R., Palatella, L., Borra, M., Marullo, S., Hochscheid, S., Lacorata, G., Iudicone, D., 2016. Seasonal heterogeneity of ocean warming: a mortality sink for ectotherm 890 colonizers. Scientific Reports 6, 23983.

891 Magnuson, J.J., Crowder, L.B., Medvick, P.A., 1979. Temperature as an ecological resource. 892 American Zoologist 19, 331-343.

893 Marcovaldi, M.A., Godfrey, M.H., Mrosovsky, N., 1997. Estimating sex ratios of loggerhead 894 turtles in Brazil from pivotal incubation durations. Canadian Journal of Zoology-Revue 895 Canadienne de Zoologie 75, 755-770.

896 Maxwell, J.A., 1987. Incubation temperature and sex determination in Caretta caretta fron 897 Tongaland, Natal, South Africa, Department of Zoology. University of Durban-Westville, p. 898193.

899 Mazaris, A., Kallimanis, A., Sgardelis, S., Pantis, J., 2008. Do long-term changes in sea 900 surface temperature at the breeding areas affect the breeding dates and reproduction 901 performance of Mediterranean loggerhead turtles? Implications for climate change. Journal of 902 Experimental Marine Biology and Ecology 367, 219-226. 
Mazaris, A.D., Kallimanis, A.S., Pantis, J.D., Hays, G.C., 2013. Phenological response of sea turtles to environmental variation across a species' northern range. Proceedings of the Royal Society B-Biological Sciences 280, 20122397.

Mazaris, A.D., Kallimanis, A.S., Tzanopoulos, J., Sgardelis, S.P., Pantis, J.D., 2009. Sea

surface temperature variations in core foraging grounds drive nesting trends and phenology of loggerhead turtles in the Mediterranean Sea. Journal of Experimental Marine Biology and Ecology 379, 23-27.

McGaugh, S.E., Janzen, F.J., 2011. Effective heritability of targets of sex-ratio selection under environmental sex determination. Journal of Evolutionary Biology 24, 784-794.

McLachlan, J.S., Hellmann, J.J., Schwartz, M.W., 2007. A framework for debate of assisted migration in an era of climate change. Conservation Biology 21, 297-302.

Miller, J.D., 1985. Embryology of marine turtles, in: Gans, C., Billet, F., Maderson, P.F. (Eds.), Biology of the Reptilia. Wiley-Liss, New-York, US, pp. 270-328.

Miller, J.D., 1997. Reproduction in sea turtles, in: Lutz, P.L., Musick, J.A. (Eds.), The Biology of Sea Turtles. CRC Press, New York, USA, pp. 51-81.

Mitchell, N.J., Allendorf, F.W., Keall, S.N., Daugherty, C.H., Nelson, N.J., 2010.

Demographic effects of temperature-dependent sex determination: will tuatara survive global warming? Global Change Biology 16, 60-72.

Mitchell, N.J., Kearney, M.R., Nelson, N.J., Porter, W.P., 2008. Predicting the fate of a living fossil: how will global warming affect sex determination and hatching phenology in tuatara? Proceedings of the Royal Society B-Biological Sciences 275, 2185-2193.

Mitchell, N.J., Rodriguez, N., Kuchling, G., Arnall, S.G., Kearney, M.R., 2016. Reptile embryos and climate change: modelling limits of viability to inform translocation decisions. Biological Conservation 204, 134-147. 
Monsinjon, J., Guillon, J.-M., Hulin, V., Girondot, M., 2017a. Modelling the Sex Ratio of Natural Clutches of the European Pond Turtle, Emys orbicularis (L., 1758), from Air Temperature. Acta Zoologica Bulgarica Suppl. 10, 105-113.

Monsinjon, J., Jribi, I., Hamza, A., Ouerghi, A., Kaska, Y., Girondot, M., 2017b. Embryonic growth rate thermal reaction norm of Mediterranean Caretta caretta embryos from two different thermal habitats, Turkey and Libya. Chelonian Conservation and Biology 16, 172179.

Monsinjon, J., López-Mendilaharsu, M., Lara, P., Santos, A., dei Marcovaldi, M.A.G., Girondot, M., Fuentes, M.M.P.B., 2019. Effects of temperature and demography on the phenology of loggerhead sea turtles in Brazil. Marine Ecology Progress Series 623, 209-219. Montero, N., Ceriani, S.A., Graham, K., Fuentes, M.M.P.B., 2018a. Influences of the Local Climate on Loggerhead Hatchling Production in North Florida: Implications From Climate Change. Frontiers in Marine Science 5, 1-11.

Montero, N., Marcovaldi, M.A.G.d., Lopez-Mendilaharsu, M., Santos, A.S., Santos, A.J.B., Fuentes, M.M.P.B., 2018b. Warmer and wetter conditions will reduce offspring production of hawksbill turtles in Brazil under climate change. PLoS One 13, e0204188.

Montero, N., Tomillo, P.S., Saba, V.S., Marcovaldi, M.A.G.d., López-Mendilaharsu, M., Santos, A.S., Fuentes, M.M.P.B., 2019. Effects of local climate on loggerhead hatchling production in Brazil: Implications from climate change. Scientific Reports 9, 8861. Moss, R.H., Edmonds, J.A., Hibbard, K.A., Manning, M.R., Rose, S.K., Vuuren, D.P.v., Carter, T.R., Emori, S., Kainuma, M., Kram, T., Meehl, G.A., Mitchell, J.F.B., Nakicenovic, N., Riahi, K., Smith, S.J., Stouffer, R.J., Thomson, A.M., Weyant, J.P., Wilbanks, T.J., 2010. The next generation of scenarios for climate change research and assessment. Nature 463, 747-756. 
Mrosovsky, N., 1988. Pivotal temperatures for loggerhead turtles (Caretta caretta) from northern and southern nesting beaches. Canadian Journal of Zoology-Revue Canadienne de Zoologie 66, 661-669.

Mrosovsky, N., 2006. Distorting gene pools by conservation: Assessing the case of doomed turtle eggs. Environmental Management 38, 523-531.

Mrosovsky, N., Kamel, S., Rees, A.F., Margaritoulis, D., 2002. Pivotal temperature for loggerhead turtles (Caretta caretta) from Kyparissia Bay, Greece. Canadian Journal of Zoology-Revue Canadienne de Zoologie 80, 2118-2124.

Neeman, N., Robinson, N.J., Paladino, F.V., Spotila, J.R., O'Connor, M.P., 2015. Phenology shifts in leatherback turtles (Dermochelys coriacea) due to changes in sea surface temperature. Journal of Experimental Marine Biology and Ecology 462, 113-120.

Nel, R., Punt, A.E., Hughes, G.R., 2013. Are coastal protected areas always effective in achieving population recovery for nesting sea turtles? PLoS One 8, e63525.

Nelson, N.J., Keall, S.N., Refsnider, J.M., Carter, A.L., 2018. Behavioral variation in nesting phenology may offset sex-ratio bias in tuatara. Journal of Experimental Zoology Part A:

Ecological and Integrative Physiology 329, 373-381.

Neuwald, J.L., Valenzuela, N., 2011. The lesser known challenge of climate change: thermal variance and sex-reversal in vertebrates with temperature-dependent sex determination. PLoS One 6, e18117.

Nogués-Bravo, D., Rodríguez-Sánchez, F., Orsini, L., De Boer, E., Jansson, R., Morlon, H., Fordham, D.A., Jackson, S.T., 2018. Cracking the code of biodiversity responses to past climate change. Trends in Ecology \& Evolution 33, 765-776.

Parmesan, C., 2006. Ecological and evolutionary responses to recent climate change. Annual Review of Ecology, Evolution, and Systematics 37, 637-669. 
975 Patel, S.H., Morreale, S.J., Saba, V.S., Panagopoulou, A., Margaritoulis, D., Spotila, J.R., 976 2016. Climate impacts on sea turtle breeding phenology in Greece and associated foraging 977 habitats in the Wider Mediterranean Region. PLoS One 11, e0157170.

978 Patrício, A.R., Varela, M.R., Barbosa, C., Broderick, A.C., Catry, P., Hawkes, L.A., Regalla, 979 A., Godley, B.J., 2018. Climate change resilience of a globally important sea turtle nesting 980 population. Global Change Biology 25, 522-535.

981 Pieau, C., Dorizzi, M., 1981. Determination of temperature sensitive stages for sexual 982 differentiation of the gonads in embryos of the turtle, Emys orbicularis. Journal of 983 Morphology 170, 373-382.

984 Pike, D.A., 2013. Climate influences the global distribution of sea turtle nesting. Global 985 Ecology and Biogeography 22, 555-566.

986 Pike, D.A., Antworth, R.L., Stiner, J.C., 2006. Earlier nesting contributes to shorter nesting 987 seasons for the loggerhead sea turtle, Caretta caretta. Journal of Herpetology 40, 91-94.

988 Poloczanska, E.S., Limpus, C.J., Hays, G.C., 2009. Vulnerability of marine turtles to climate 989 change. Advances in Marine Biology 56, 151-211.

990 Porter, W.P., Ostrowski, S., Williams, J.B., 2010. Modeling Animal Landscapes.

991 Physiological and Biochemical Zoology 83, 705-712.

992 R Core Team, 2019. R: A language and environment for statistical computing, R version 3.5.3 993 ed. R Foundation for Statistical Computing, Vienna, Austria.

994 Rafferty, A.R., Johnstone, C.P., Garner, J.A., Reina, R.D., 2017. A 20-year investigation of 995 declining leatherback hatching success: implications of climate variation. Royal Society open 996 science 4, 170196.

997 Read, T., Booth, D.T., Limpus, C.J., 2013. Effect of nest temperature on hatchling phenotype 998 of loggerhead turtles (Caretta caretta) from two South Pacific rookeries, Mon Repos and La 999 Roche Percée. Australian Journal of Zoology 60, 402-411. 
Refsnider, J.M., Janzen, F.J., 2012. Behavioural plasticity may compensate for climate change in a long-lived reptile with temperature-dependent sex determination. Biological Conservation $152,90-95$

Refsnider, J.M., Janzen, F.J., 2015. Temperature-dependent sex determination under rapid anthropogenic environmental change: Evolution at a turtle's pace? Journal of Heredity 107, $61-70$.

Refsnider, J.M., Warner, D.A., Janzen, F.J., 2013. Does shade cover availability limit nest-site choice in two populations of a turtle with temperature-dependent sex determination? Journal of Thermal Biology 38, 152-158.

Root, T.L., Price, J.T., Hall, K.R., Schneider, S.H., Rosenzweigk, C., Pounds, J.A., 2003. Fingerprints of global warming on wild animals and plants. Nature 421, 57-60.

Saba, V.S., Stock, C.A., Spotila, J.R., Paladino, F.V., Santidrián Tomillo, P., 2012. Projected response of an endangered marine turtle population to climate change. Nature Climate Change $2,814-820$

Santidrián Tomillo, P., Genovart, M., Paladino, F.V., Spotila, J.R., Oro, D., 2015a. Climate change overruns resilience conferred by temperature-dependent sex determination in sea turtles and threatens their survival. Global Change Biology 21, 2980-2988.

Santidrián Tomillo, P., Oro, D., Paladino, F.V., Piedra, R., Sieg, A.E., Spotila, J.R., 2014. High beach temperatures increased female-biased primary sex ratios but reduced output of female hatchlings in the leatherback turtle. Biological Conservation 176, 71-79.

Santidrián Tomillo, P., Saba, V.S., Lombard, C.D., Valiulis, J.M., Robinson, N.J., Paladino, F.V., Spotila, J.R., Fernandez, C., Rivas, M.L., Tucek, J., Nel, R., Oro, D., 2015b. Global analysis of the effect of local climate on the hatchling output of leatherback turtles. Scientific Reports 5, 16789. 
Schwanz, L., Janzen, F., 2008. Climate change and temperature-dependent sex determination: can individual plasticity in nesting phenology prevent extreme sex ratios? Physiological and Biochemical Zoology 81, 826-834.

Sella, K., Fuentes, M.M.P.B., 2019. Exposure of Marine Turtle Nesting Grounds to Coastal Construction: implications for management. Journal of Ocean and Coastal Management 169, 182-190.

Shamblin, B.M., Bolten, A.B., Abreu-Grobois, F.A., Bjorndal, K.A., Cardona, L., Carreras, C., Clusa, M., Monzón-Argüello, C., Nairn, C.J., Nielsen, J.T., Nel, R., Soares, L.S., Stewart, K.R., Vilaça, S.T., Türkozan, O., Yilmaz, C., Dutton, P.H., 2014. Geographic patterns of genetic variation in a broadly distributed marine vertebrate: New insights into loggerhead turtle stock structure from expanded mitochondrial DNA Sequences. PLoS One 9, e85956. Socolar, J.B., Epanchin, P.N., Beissinger, S.R., Tingley, M.W., 2017. Phenological shifts conserve thermal niches in North American birds and reshape expectations for climate-driven range shifts. PNAS 114, 12976-12981.

Stubbs, J.L., Kearney, M.R., Whiting, S.D., Mitchell, N.J., 2014. Models of primary sex ratios at a major flatback turtle rookery show an anomalous masculinising trend. Climate Change Responses 1, 1-17.

Tedeschi, J.N., Kennington, W.J., Tomkins, J.L., Berry, O., Whiting, S., Meekan, M.G., Mitchell, N.J., 2016. Heritable variation in heat shock gene expression: a potential mechanism for adaptation to thermal stress in embryos of sea turtles. Proceedings of the Royal Society B: Biological Sciences 283, 20152320.

Telemeco, R.S., Abbott, K.C., Janzen, F.J., 2013. Modeling the effects of climate-change induced shifts in reproductive phenology on temperature-dependent traits. American Naturalist 181, 637-648. 
Tewksbury, J.J., Huey, R.B., Deutsch, C.A., 2008. Putting the Heat on Tropical Animals. Science 320, 1296.

Valverde, R.A., Wingard, S., Gómez, F., Tordoir, M.T., Orrego, C.M., 2010. Field lethal incubation temperature of olive ridley sea turtle Lepidochelys olivacea embryos at a mass nesting rookery. Endangered Species Research 12, 77-86.

Visser, M.E., 2008. Keeping up with a warming world; assessing the rate of adaptation to climate change. Proceedings of the Royal Society B: Biological Sciences 275, 649-659. Visser, M.E., te Marvelde, L., Lof, M.E., 2012. Adaptive phenological mismatches of birds and their food in a warming world. Journal of Ornithology 153, 75-84.

Wallace, B.P., DiMatteo, A.D., Hurley, B.J., Finkbeiner, E.M., Bolten, A.B., Chaloupka, M.Y., Hutchinson, B.J., Abreu-Grobois, F.A., Amorocho, D., Bjorndal, K.A., Bourjea, J., Bowen, B.W., Dueñas, R.B., Casale, P., Choudhury, B.C., Costa, A., Dutton, P.H., Fallabrino, A., Girard, A., Girondot, M., Godfrey, M.H., Hamann, M., López-Mendilaharsu, M., Marcovaldi, M.A., Mortimer, J.A., Musick, J.A., Nel, R., Seminoff, J.A., Troëng, S., Witherington, B., Mast, R.B., 2010. Regional management units for marine turtles: a novel framework for prioritizing conservation and research across multiple scales. PLoS One 5, e15465.

Walther, G.-R., 2010. Community and ecosystem responses to recent climate change. Philosophical Transactions of the Royal Society B-Biological Sciences 365, 2019-2024. Weishampel, J.F., Bagley, D.A., Ehrhart, L.M., 2004. Earlier nesting by loggerhead sea turtles following sea surface warming. Global Change Biology 10, 1424-1427.

Weishampel, J.F., Bagley, D.A., Ehrhart, L.M., Weishampel, A.C., 2010. Nesting phenologies of two sympatric sea turtle species related to sea surface temperatures. Endangered Species Research 12, 41-47. 
1072 Wold, C., 2002. The status of sea turtles under international environmental law and

1073 international environmental agreements. Journal of International Wildlife Law and Policy 5,

$1074 \quad 11-48$.

1075 Wood, A., Booth, D.T., Limpus, C.J., 2014. Sun exposure, nest temperature and loggerhead

1076 turtle hatchlings: Implications for beach shading management strategies at sea turtle

1077 rookeries. Journal of Experimental Marine Biology and Ecology 451, 105-114.

1078 Woolgar, L., Trocini, S., Mitchell, N., 2013. Key parameters describing temperature-

1079 dependent sex determination in the southernmost population of loggerhead sea turtles. Journal 1080 of Experimental Marine Biology and Ecology 449, 77-84.

1081 Wright, L.I., Stokes, K.L., Fuller, W.J., Godley, B.J., McGowan, A., Snape, R., Tregenza, T.,

1082 Broderick, A.C., 2012. Turtle mating patterns buffer against disruptive effects of climate

1083 change. Proceedings of the Royal Society B: Biological Sciences 279, 2122-2127.

1084 Yntema, C.L., Mrosovsky, N., 1980. Sexual differentiation in hatchling loggerheads (Caretta

1085 caretta) incubated at different controlled temperatures. Herpetologica 36, 33-36.

1086 Yntema, C.L., Mrosovsky, N., 1982. Critical periods and pivotal temperatures for sexual

1087 differentiation in loggerhead sea turtles. Canadian Journal of Zoology-Revue Canadienne de 1088 Zoologie 60, 1012-1016.

\section{FIGURES}




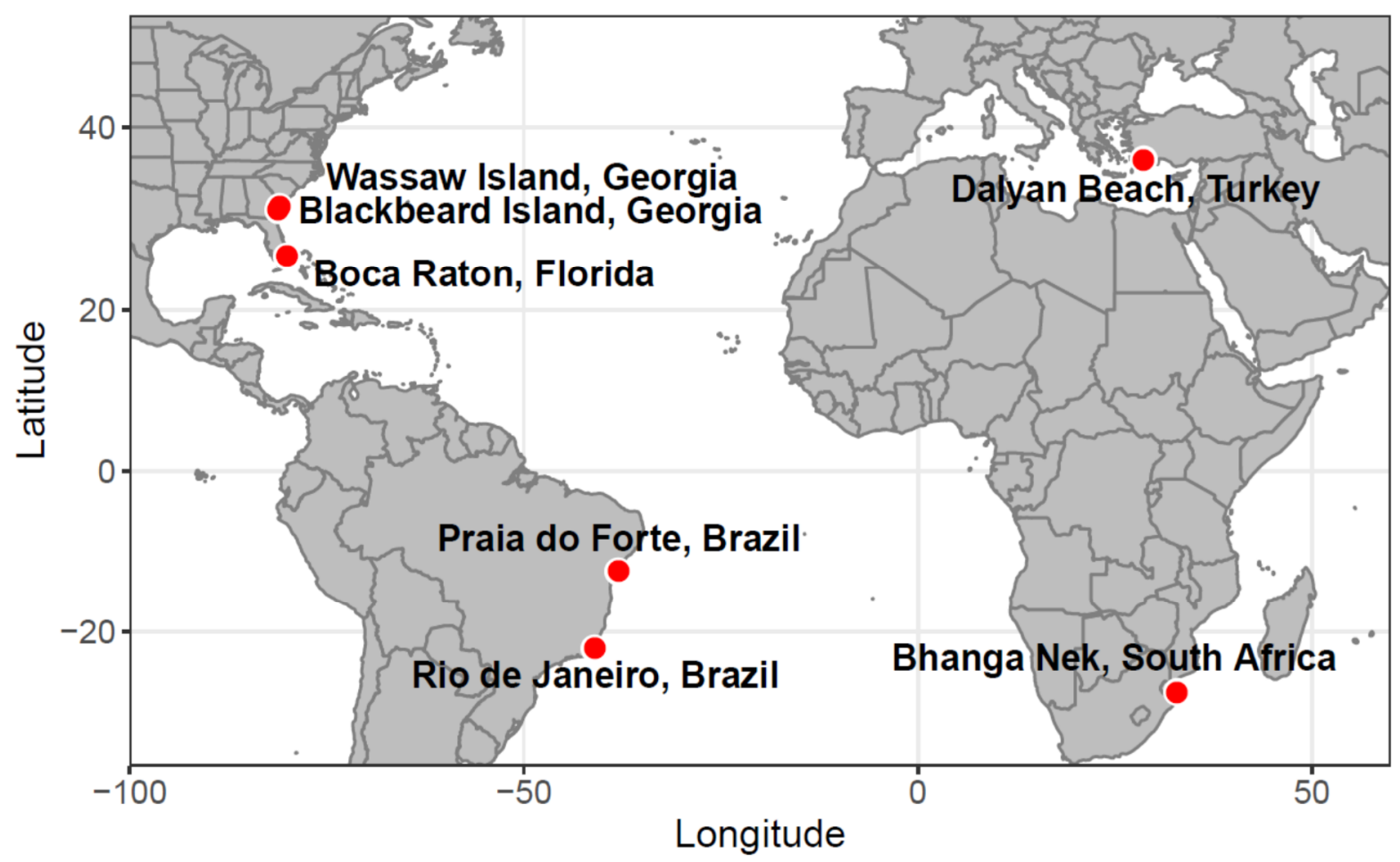

1092

1093 Legend: Locations of the seven nesting sites studied (red dots) within four Regional 1094 Management Units (RMUs): Mediterranean (Dalyan Beach, Turkey), Northwest Atlantic 1095 (Boca Raton, Florida, USA, Wassaw Island and Blackbeard Island, Georgia, USA), 1096 Southwest Atlantic (Praia do Forte and Rio de Janeiro, Brazil) and Southwest Indian (Bhanga 1097 Nek, South Africa).

1098

Figure 2. Conceptual approach to calculating the climatic debt 


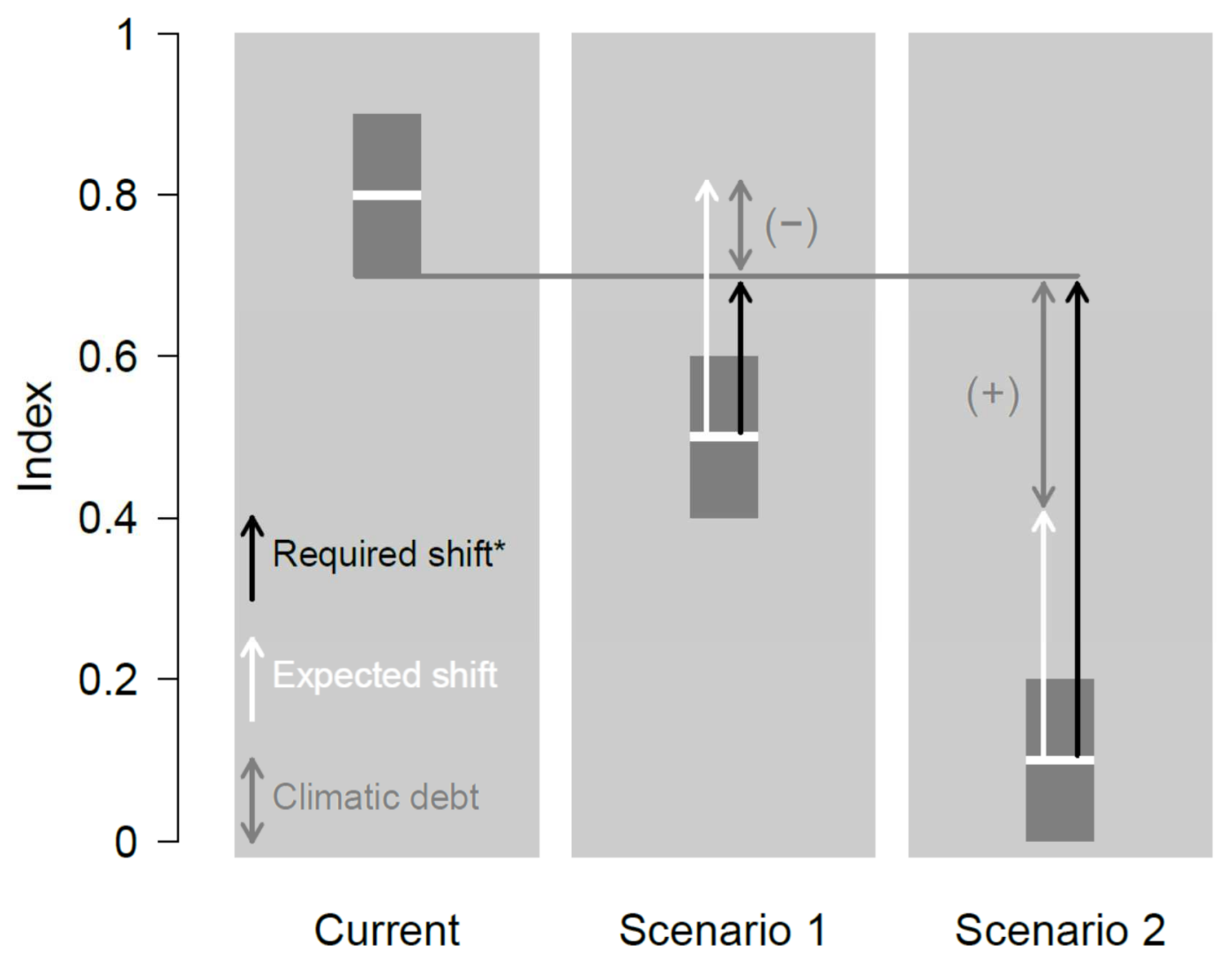

1101 Legend: Grey bars represent the range of current and projected indices (quantiles at 25\% and $110275 \%$ ) assuming no phenological shifts (under two warming scenarios) and white dashes 1103 represent quantiles at 50\%. Black arrows represent the change in the index value required for 1104 the quantile at $50 \%$ of projected indices to reach the lower limit of current indices $(*$ i.e., shift required to "pay" what we define as the climatic price). White arrows represent the change in 1106 the index value resulting from expected temperature-induced phenological shifts. Grey 1107 double-headed arrows represent the change in the index values according to the climatic 1108 scenario, after considering the expected phenological shift (i.e., the effect of what we define 1109 as the climatic debt). A negative climatic debt (-) is a situation where the expected 1110 phenological shift can effectively offset future climatic change, whereas a positive climatic 1111 debt $(+)$ is the opposite situation. 


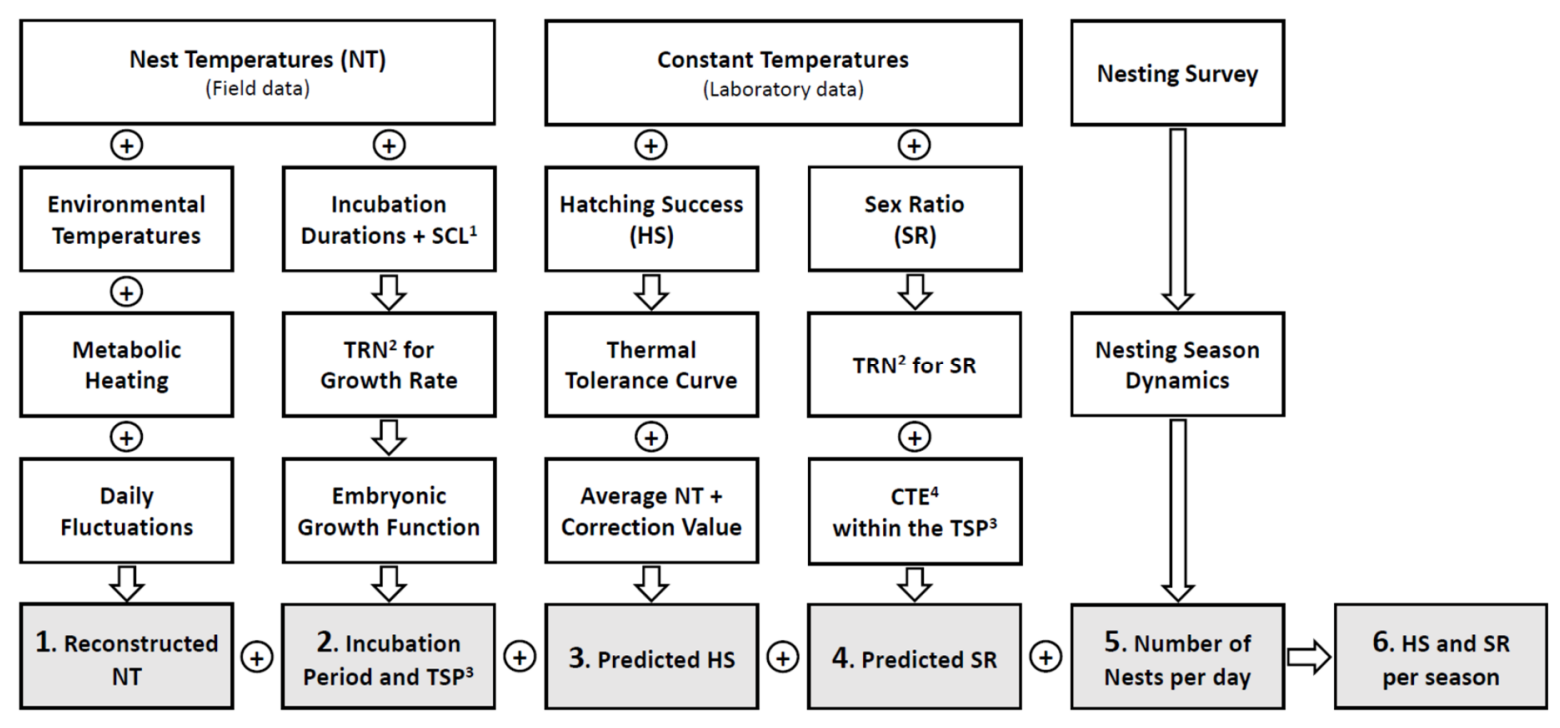

1115 Legend: (1) Reconstructing nest temperature, (2) Modeling embryonic development, (3)

1116 Estimating hatching success, (4) Estimating sex ratio, (5) Unraveling the dynamics of nesting

1117 activity and (6) Calculating hatching success and sex ratio indices (see Methods).

1118 Abbreviations: ${ }^{1}$ Straight Carapace Length (SCL) of hatchlings, ${ }^{2}$ Thermal Reaction Norm

1119 (TRN), ${ }^{3}$ ThermoSensitive Period (TSP) of development for sex determination and ${ }^{4}$ Constant

1120 Temperature Equivalent (CTE). Plus marks (+) indicate data required to infer a model and

1121 arrows lead to a result. 

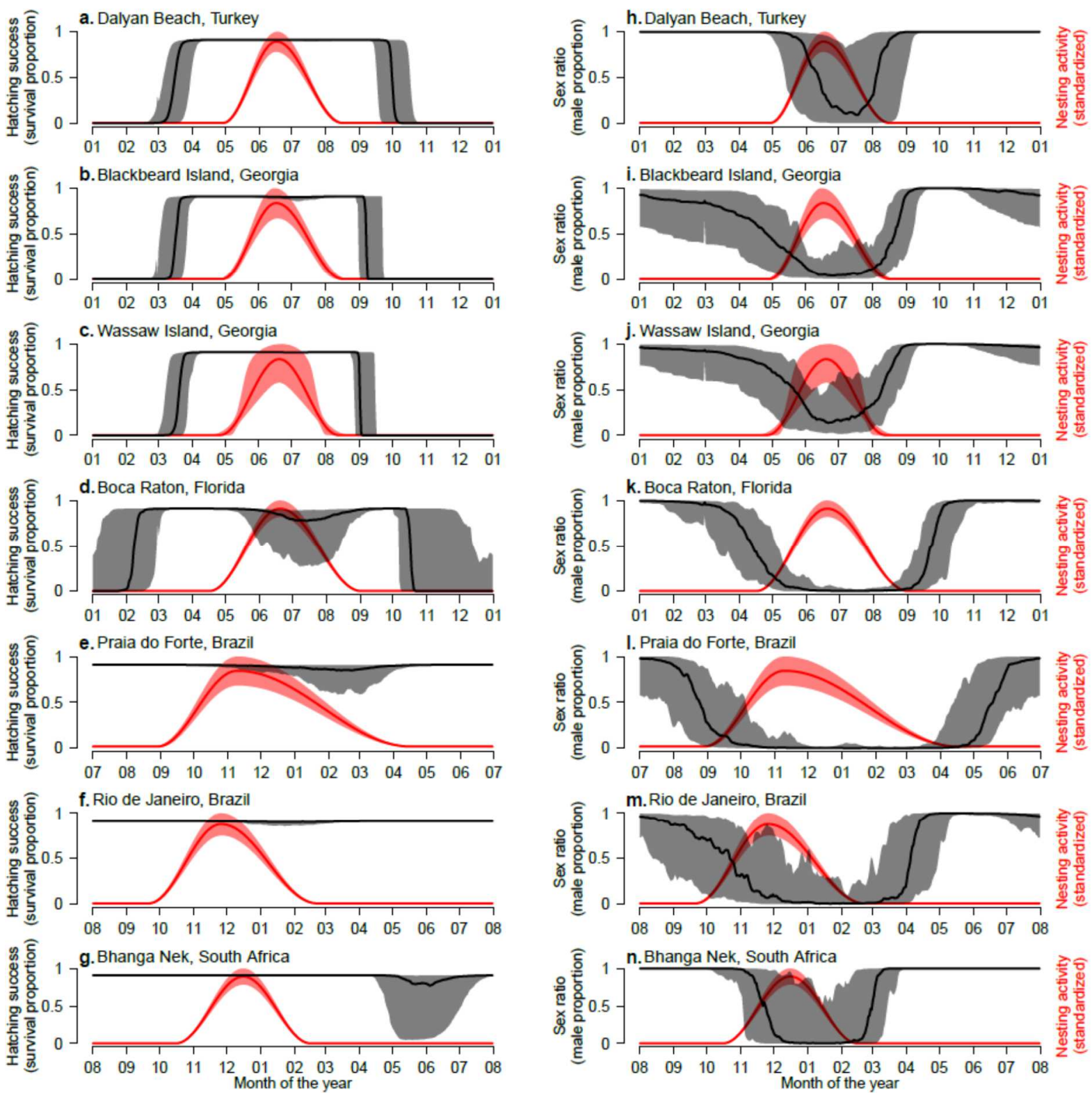

1125 Legend: Current hatching success and sex ratio (quantiles at 50\%, black lines) for any days

1126 throughout the season with lower and upper quantiles (respectively, at $2.5 \%$ and $97.5 \%$, grey

1127 areas) are shown for populations nesting at Dalyan Beach, Turkey (respectively, $\mathbf{a}$ and $\mathbf{h}$ ), at

1128 Blackbeard Island, Georgia, USA (respectively, b and l), at Wassaw Island, Georgia, USA

1129 (respectively, $\mathbf{c}$ and $\mathbf{j}$ ), at Boca Raton, Florida, USA (respectively, $\mathbf{d}$ and $\mathbf{k}$ ), at Praia do Forte,

1130 Brazil (respectively, e and l), at Rio de Janeiro, Brazil (respectively, $\mathbf{f}$ and $\mathbf{m}$ ) and at Bhanga

1131 Nek, South Africa (respectively, $\mathbf{g}$ and $\mathbf{n}$ ). Quantiles were calculated based on 1979-2016 time

series. Standardized nesting activity (number of nests laid throughout the season based on the 
1133 global description of nesting activity) is indicated by red lines and the confidence interval at

$113495 \%$ is indicated by red shaded areas. Note that the first month on the $\mathrm{x}$-axis differs according

1135 to the nesting site.

1136

1137 Figure 5. Warming temperatures may reduce hatching success and induce a 1138 feminization of hatchlings 


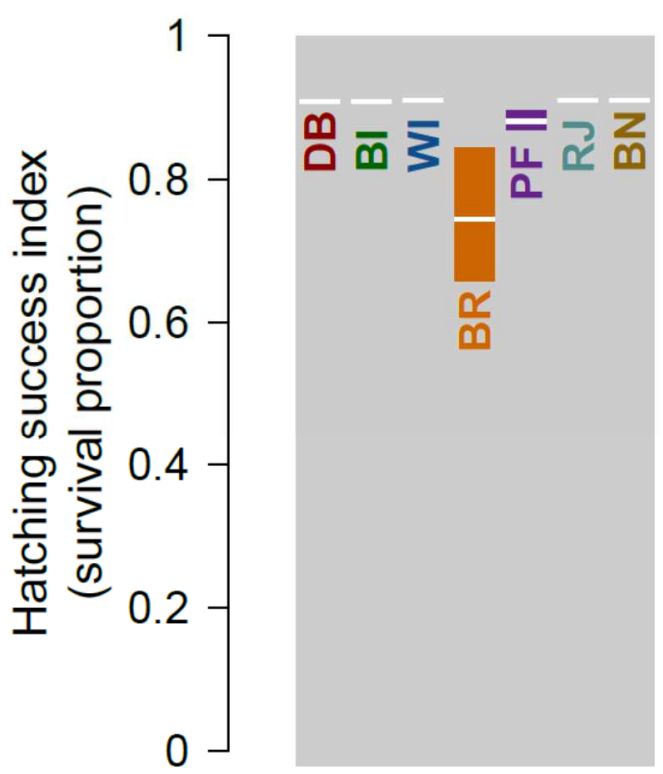

Current

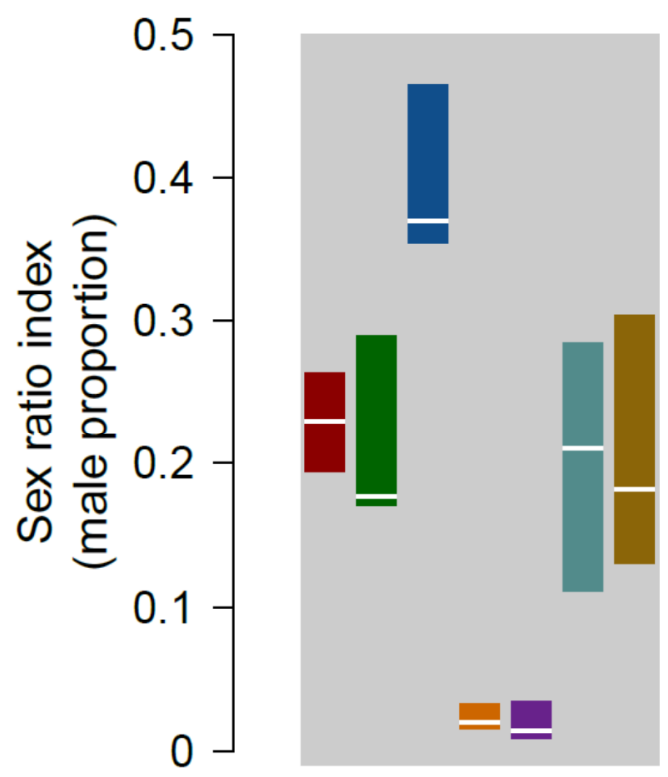

Current

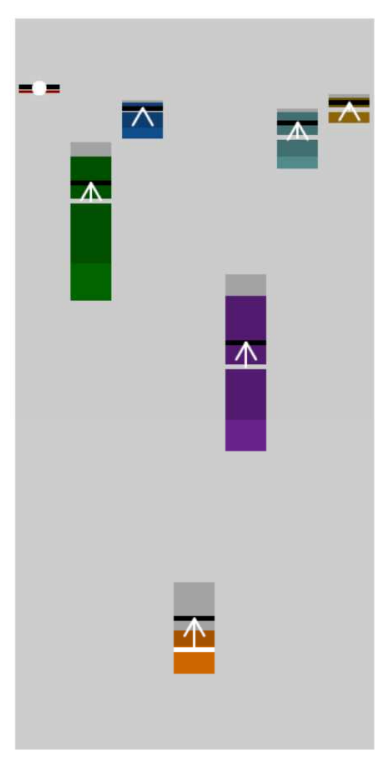

RCP4.5

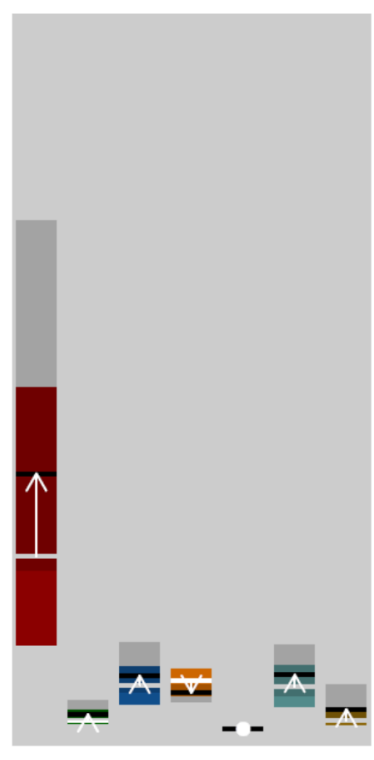

RCP4.5

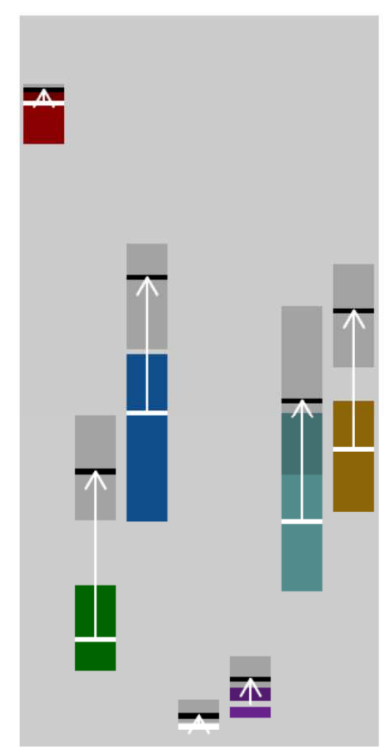

a

RCP8.5

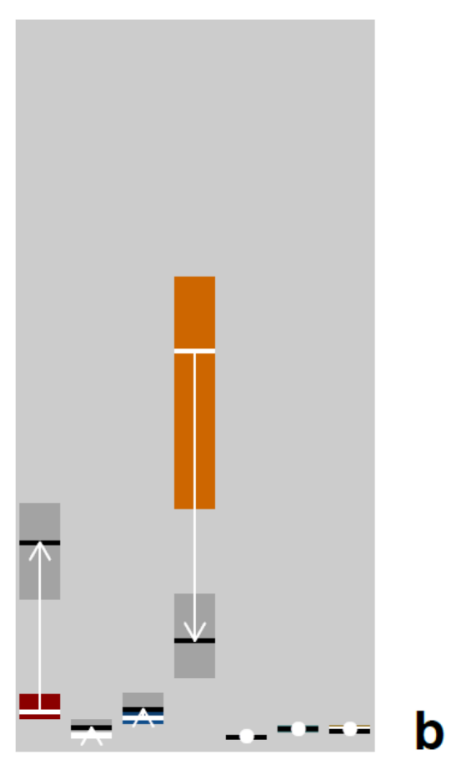

RCP8.5

1140 Legend: Current hatching success (a) and sex ratio (b) indices are shown (left panels) with

1141 projected ones (middle [RCP4.5] and right [RCP8.5] panels): (i) assuming no phenological

1142 shift (colored bars and white dashes) and (ii) considering expected phenological shifts (grey

1143 shaded bars and black dashes). Colored or grey shaded areas show lower and upper quantiles

1144 (respectively, at 25\% and 75\%), which give a measure of the interseasonal variability, and

1145 white or black dashes indicate quantiles at 50\%. White arrows represent changes in the value 
of indices if expected phenological shifts are considered and white dots represent the situation where changes in the value of indices are $<0.002$. Current indices were calculated based on seasons when nests were surveyed (using the "season-specific description" of nesting activity, see Methods): $\mathrm{n}=6$ at Dalyan Beach (DB), $\mathrm{n}=3$ at Blackbeard Island (BI), $\mathrm{n}=5$ at Wassaw Island (WI), $\mathrm{n}=16$ at Boca Raton $(\mathbf{B R}), \mathrm{n}=26$ at Praia do Forte $(\mathbf{P F}), \mathrm{n}=14$ at Rio de Janeiro (RJ) and $n=32$ at Bhanga Nek $(\mathbf{B N})$. Projected indices (i.e., forecasts for the 20622100 period) were calculated under two scenarios for future Representative Concentration Pathways (RCPs) in greenhouse gas concentration (an optimistic scenario and a pessimistic scenario, respectively RCP4.5 and RCP8.5) and based on all future seasons ( $n=38)$ using the "global description" of nesting activity (see Methods).

\section{TABLES}

Table 1. Differences between required and expected phenological shifts (climatic debts)

\begin{tabular}{rccc}
\hline Nesting site & Index & $\begin{array}{c}\text { RCP4.5 } \\
\text { (number of days) }\end{array}$ & $\begin{array}{c}\text { RCP8.5 } \\
\text { (number of days) }\end{array}$ \\
\hline Dalyan Beach, Turkey & HSI & $0-8.3=\mathbf{- 8 . 3}$ & $21-20.2=\mathbf{0 . 8}$ \\
& SRI & $10-8.3=\mathbf{1 . 7}$ & $26-20.2=\mathbf{5 . 8}$ \\
Blackbeard Island, Georgia & HSI & $50-8.3=\mathbf{4 1 . 7}$ & $81-20.2=\mathbf{6 0 . 8}$ \\
& SRI & $53-8.3=\mathbf{4 4 . 7}$ & $67-20.2=\mathbf{4 6 . 8}$ \\
\hline Wassaw Island, Georgia & HSI & $52-8.3=\mathbf{4 3 . 7}$ & $76-20.2=\mathbf{5 5 . 8}$ \\
& SRI & $58-8.3=\mathbf{4 9 . 7}$ & $74-20.2=\mathbf{5 3 . 8}$ \\
\hline Boca Raton, Florida & HSI & $54-8.3=\mathbf{4 5 . 7}$ & $90-20.2=\mathbf{6 9 . 8}$ \\
& SRI & $*$ & $*$ \\
\hline Praia do Forte, Brazil & HSI & $104-8.3=\mathbf{9 5 . 7}$ & none \\
& SRI & $79-8.3=\mathbf{7 0 . 7}$ & none \\
\hline Rio de Janeiro, Brazil & HSI & $43-8.3=\mathbf{3 4 . 7}$ & $118-20.2=\mathbf{9 7 . 8}$ \\
& SRI & $37-8.3=\mathbf{2 8 . 7}$ & $112-20.2=\mathbf{9 1 . 8}$ \\
\hline Bhanga Nek, South Africa & HSI & $27-8.3=\mathbf{1 8 . 7}$ & $81-20.2=\mathbf{6 0 . 8}$ \\
& SRI & $34-8.3=\mathbf{2 5 . 7}$ & $77-20.2=\mathbf{5 6 . 8}$
\end{tabular}

Legend: This Table shows the shifting of nesting phenology (in minimum number of days earlier) required for projected Hatching Success Indices (HSIs in survival proportion: white rows) and Sex Ratio Indices (SRIs in male proportion: grey rows) (quantiles at 50\%) to 
1162 remain within current ranges (i.e., beyond quantiles at $25 \%$ of current indices) under two

1163 scenarios of Representative Concentration Pathways (RCPs) of greenhouse gas concentration:

1164 an optimistic scenario (RCP4.5) and a pessimistic scenario (RCP8.5). Climatic scenarios

1165 reflect future temperature changes (2062-2100) as compared to current thermal conditions

1166 (1979-2016). Climatic debts (values in bold) are calculated by subtracting expected

1167 phenological shifts (8.3 and 20.2 days earlier, respectively for RCP4.5 and RCP8.5) from

1168 required ones (i.e., climatic prices: values in italics). Negative values indicate that

1169 phenological shifts can effectively offset future changes, positive values indicate the opposite

1170 situation, and "none" means that no climatic price was found. *Climatic debts were not

1171 calculated because projected SRIs lie within or above the range of current indices. 